\title{
FATORES CONDICIONANTES NA RECARGA DO AQÜÍFERO AÇU NA BORDA SUDOESTE DA BACIA POTIGUAR (RN)
}

\section{CONDITIONING FACTORS OF THE ACU AQUIFER RECHARGE ON THE SOUTHWEST BORDER OF THE POTIGUAR BASIN, RIO GRANDE DO NORTE STATE, BRAZIL.}

\author{
José Geraldo de Melo'; Paula Stein ${ }^{1}$; \\ Mickaelon Belchior Vasconcelos ${ }^{1}$ e Fabio Henrique Roque da Silva ${ }^{1}$
}

Recebido em: 29/03/2005; aceito em: 25/09/2005

\begin{abstract}
RESUMO A Borda Sudoeste da Bacia Potiguar, no Rio Grande do Norte, está situada em domínio semi-árido com precipitações pluviométricas médias de 765,1 mm/ano. O aquífero Açu é o principal recurso hídrico disponível para o suprimento das populações com água potável e uso na irrigação, desempenhando, portanto um papel importante no desenvolvimento da região. A captação de água é feita através de poços, os quais fornecem vazões muito variadas, desde menos de $5 \mathrm{~m}^{3} / \mathrm{h}$ até $80 \mathrm{~m}^{3} / \mathrm{h}$, atestando condições de heterogeneidade, o que tem limitado o uso das águas subterrâneas em maior escala. Os dados geológicos, estruturais e geofísicos (sondagens elétricas verticais e condutância longitudinal) mostram que a área é formada por altos e baixos estruturais. De conformidade com os resultados dos estudos hidrogeológicos realizados, isto condiciona a ocorrência de setores com diferentes potencialidades. Verificou-se que a transmissividade do aqüífero cresce no sentido de sul para norte segundo a direção do fluxo subterrâneo, com valores de menos de $10 \mathrm{~m}^{2} / \mathrm{dia}$ até $280 \mathrm{~m}^{2} /$ dia, evidenciando, portanto maiores potencialidades do aqǘf́ero Açu na faixa norte da área. A recarga das águas subterrâneas foi avaliada em 54 milhões de $\mathrm{m}^{3} /$ ano, sendo que mais de $90 \%$ deste recurso é armazenado no setor norte da área.
\end{abstract}

Palavras chave: Semi-árido, água subterrânea, recarga, fluxo subterrâneo.

ABSTRACT The Potiguar Basin Southwest border, on Rio Grande do Norte State, is situated in the semi-arid region and the precipitation is about $765.1 \mathrm{~mm} /$ year. The Açu aquifer is the main water source of supply to the population and to land irrigation. The wells bored in the area, however presents very different production, whose yields go from less them $5 \mathrm{~m}^{3} / \mathrm{h} \mathrm{up}$ to $60 \mathrm{~m}^{3} / \mathrm{h}$. It is the main reason of limiting the use of the groundwater. As shown by the geological, structural e geophysical dates (vertical electrical profiles and longitudinal conductance) there are high and low geological structures. According to the studies carried out, these characteristics results in various sectors of different hydrogeologic potentialities. The aquifer transmissisvity increases following the flux direction from south to north, changing from less than $10 \mathrm{~m}^{2} / \mathrm{d}$ to $280 \mathrm{~m}^{2} / \mathrm{d}$, characterizing the north zone of the area as the best hydrogeologic possibilities. The groundwater recharge was estimated in 54 millions $\mathrm{m}^{3} /$ year, in which most of it $(91.5 \%)$ is stored in the north zone of the area.

Keywords: semi-arid, groundwater, recharge, groundwater flow.

\section{INTRODUÇÃO}

A área de estudo está situada na borda sudoeste da Bacia Potiguar à oeste do Estado do Rio Grande do Norte, numa estreita faixa de direção leste-oeste que se estende de Upanema até a fronteira com o Estado do Ceará, ocupando uma superfície de $1320 \mathrm{~km}^{2}$ (Figura 1).

As águas subterrâneas do aqüífero Açu têm sido destinadas, prioritariamente, ao abastecimento das cidades de Apodi, Upanema, Felipe Guerra, Rodolfo Fernandes e Severiano Melo, além de distritos, ressaltando que essas duas últimas cidades e alguns dos distritos estão situados no domínio das rochas cristalinas, onde as águas superficiais e subterrâneas são escassas e em geral salinizadas. Nestes casos, o abastecimento de água é feito através de sistema de adutoras.

A captação de água no aqüífero Açu em geral é feita através de poços com profundidades da ordem de $100 \mathrm{~m}$ produzindo até $80 \mathrm{~m}^{3} / \mathrm{h}$. A descarga total bombeada, obtida na fase de cadastramento de poços, é da ordem de 10 milhões de $\mathrm{m}^{3}$ /ano. O uso da água na irrigação é relativamente pouco desenvolvido, porém mostra tendências para um crescimento expressivo. Há casos, também de industrialização das águas subterrâneas do aquífero Açu como águas minerais ou potáveis de mesa, como é o caso da indústria de Água Mineral Cristalina e a industria de Água Mineral Santa Luzia, localizadas nos municípios de Apodi e Upanema, respectivamente.

Nos últimos anos o uso das águas do aqüífero tem sido limitado pela presença de águas salinizadas em alguns setores, baixas vazões dos poços em muitas situações e pela falta de conhecimento de suas reais potencialidades. O presente artigo enfatiza os aspectos estruturais e de recarga das águas subterrâneas como subsídio à otimização da explotação das águas subterrâneas. fornecem uma primeira indicação de que o aquífero Açu na zona de afloramento da Formação Açu é do tipo livre com fluxo subterrâneo dirigido para norte.

${ }^{1}$ UFRN/ Depto de Geologia/PPGEO (jgmelo@ufrnet.br), (Paulinha_st@hotmail.com), (mickvasconcelos@yahoo.com.br) 
Posteriormente, este comportamento foi confirmado por Manoel Filho (1971). Na planície do Apodi desenvolve-se o aqüífero aluvial com espessuras da ordem de $35 \mathrm{~m}$ nos seus domínios mais produtores, com cargas hidráulicas distintamente superiores as do aqüífero Açu e descarga descendente em direção ao mesmo, tendo o aquífero Açu sido caracterizado como semi-confinado (SANTOS,1977).

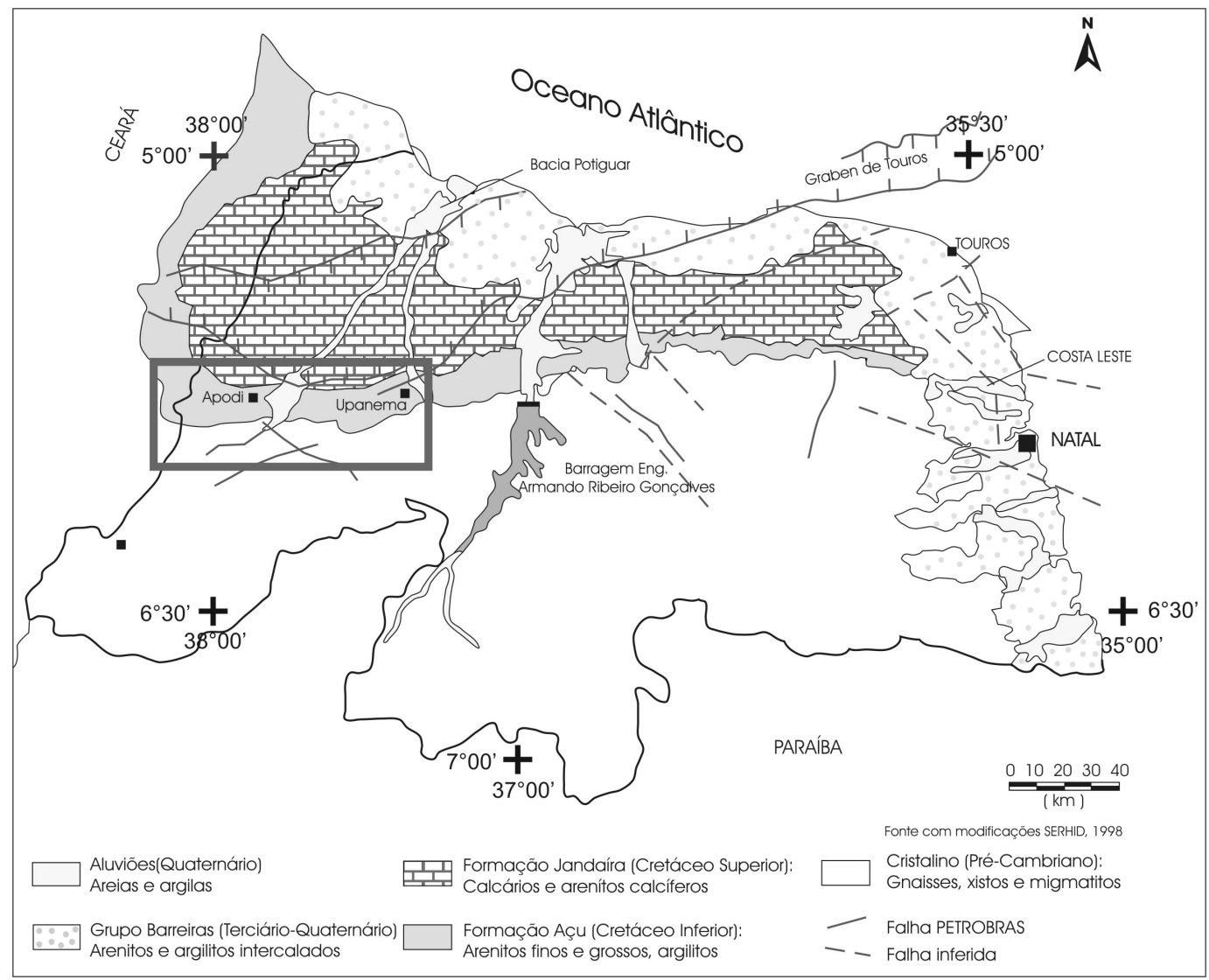

Figura 1.-Localização da área de estudo.

Figure 1-Geographic location of the Rio Grande do Norte State showing the studied region

O aqüífero Açu, segundo o IPT (1982), é de baixa potencialidade hidrogeológica na borda oeste da Bacia Potiguar,sugerindo condições de explotação de poços com vazões, no máximo, de $10 \mathrm{~m}^{3} / \mathrm{h}$. Posteriormente, a partir de 1992 , com o desenvolvimento da perfuração de poços na área, foram obtidas descargas da ordem de $60 \mathrm{~m}^{3} / \mathrm{h}$, o que motivou a Companhia de Águas e Esgotos do Rio Grande do Norte (CAERN) intensificar as perfurações, para o abastecimento de cidades.

\section{METODOLOGIA}

O trabalho foi desenvolvido segundo as seguintes atividades metodológicas:

a) Coleta e análise de dados - As atividades iniciais consistiram da coleta de dados de caráter bibliográfico, seguido de uma avaliação e sistematização das informações.

b) Cadastro de poços - Compreendeu as seguintes atividades: Identificação e localização exata de cada poço com o auxílio de GPS, e checagem das informações levantadas; medição dos parâmetros construtivos das unidades de captação, incluindo profundidade, diâmetro, altura da boca do poço e identificação do material de construção; medição e obtenção de informações sobre os parâmetros hidráulicos, tais como nível estático, nível dinâmico, vazão, vazão específica e regime de explotação; identificação do aqüífero penetrado: Jandaira, Açu ou cristalino; avaliação das condições de funcionamento do poço; finalidade do uso da água; reconhecimento da salinidade das águas com o auxílio de condutivimetro portátil.

c) Nivelamento topográfico dos poços - Foi utilizado o sistema de GPS geodésico.

d) Estrutura hidrogeológica - Foi definida com base na correlação lito-estratigráfica de perfis de poços e resultados dos estudos geofísicos.

e) Estudos geofísicos - Foram executados por uma equipe de geofísica do Departamento de Física da UFRN (MEDEIROS et al., 2001) com a utilização de método de eletroresistividade e método gravimétrico. 
f) Parâmetros hidrodinâmicos do aquiífero Açu - Foram obtidos a partir da interpretação de 41 testes de bombeamento realizados pela Companhia de Águas do Rio Grande do Norte (CAERN) e Secretaria de Recursos Hídricos do Rio Grande do Norte (SERHID/RN). Apenas um dos testes realizados dispunha de dados de poço de observação (piezômetro). A interpretação dos resultados dos testes foi efetuada com a aplicação do método de rebaixamento-tempo de Cooper-Jacob (com correção dos rebaixamentos, no caso de aqüíferos livres) e método de recuperação de Theis e Jacob. Foi utilizado o software Aquifer Test da Waterloo Hydrogeologic.

g) Caracterização do fluxo subterrâneo - Foi feita a partir da interpretação de mapa potenciométrico com base no conhecimento das cargas potenciométricas. Os dados foram importados para o software surfer, sendo em seguida elaboradas as curvas potenciométricas mediante uma cuidadosa avaliação, e posterior modificações, necessária para uma reprodução mais exata do condicionamento do fluxo no domínio aqüífero.

h) Recarga das águas subterrâneas - A recarga das águas subterrâneas foi estimada utilizando diferentes metodologias, tendo em vista a comparação de resultados e adoção de valores que se mostrassem mais representativos para o sistema hidrogeológico considerado. Foram aplicados os métodos do balanço hidroclimatólogico, variação do nível da água, Lei de Darcy aplicada ao meio poroso saturado e balanço de cloreto.

\section{CONDICIONANTES CLIMÁTICOS, GEOLÓGICOS E FISIOGRÁFICOS}

As precipitações pluviométricas no domínio da área são em média de $765,1 \mathrm{~mm}$ anuais (período1931-1990), com chuvas concentradas em três ou quatro meses, de conformidade com dados obtidos pela Empresa de Pesquisa Agropecuária do Rio Grande do Norte (EMPARN). Os dados climáticos fornecidos pela EMPARN permitiram a caracterização de um "déficit" hídrico na maior parte do ano, o que atribui a área o caráter de semi-aridez. A evapotranspiração potencial é relativamente elevada, atingindo $1542 \mathrm{~mm} /$ anuais.

$\mathrm{O}$ arcabouço geológico básico da região apresentado na Figura 2 mostra que a área de estudo é constituída de arenitos da Formação Açu, na borda sul da Bacia Potiguar, do Cretáceo Superior, com a ocorrência de depósitos Cenozóicos de paleocascalheiras de domínios restritos e coberturas aluviais recentes, com destaque para a planície aluvial do Apodi. A Formação Açu está sobreposta a rochas do embasamento cristalino pré-cambriano e o seu contato no setor sul da área se faz com estas rochas, no qual distinguem-se corpos granitóides brasilianos, o complexo gnaíssico-migmatítico e os traços de foliações e zonas de cisalhamento, de idade Brasiliana ou mais antiga. O limite norte da área se faz com os calcários da Formação Jandaira, do Cretáceo Superior, em alguns trechos envolvendo escarpas retilíneas, as quais podem corresponder a falhas ou fraturas (possível reativação neotectônica de falhas cretáceas ou terciárias, segundo Medeiros et al. (2001).

A área é cortada pelos rios Apodi e do Carmo (intermitentes) no sentido de sul para norte após drenarem os terrenos das rochas cristalinas. Seus afluentes desenvolvem uma rede de drenagem pouco densa, o que sugere reduzidos escoamentos e elevadas taxas de infiltração, o que neste caso, não chega a ocorrer devido às elevadas perdas por evapotranspiração.

$\mathrm{Na}$ paisagem regional distinguem-se diferentes formas de relevo associadas aos diferentes tipos litológicos e as estruturas geológicas. No domínio das rochas cristalinas, ao sul da área, predomina um relevo acidentado, composto por alinhamento de serras e morros isolados, desenvolvendo uma rede de drenagem dendrítica e bastante densa. Ao norte da área, tem-se a ocorrência de um relevo típico de chapada (Chapada do Apodi) formada por calcários da Formação Jandaira, com formas bastante planas e suaves variações de cotas. $\mathrm{Na}$ área de estudo, constituída por arenitos da Formação Açu, o relevo é predominantemente tabular e suavemente ondulado, com a presença de vales associados às drenagens superficiais. $\mathrm{O}$ contato da Formação Açu com os calcários da Formação Jandaira ocorre em grande parte sob a forma de escarpa abrupta.

\section{ESTRUTURA HIDROGEOLÓGICA}

A caracterização da estrutura hidrogeológica do terreno une ferramentas de análise estrutural, da geofísica e da hidrogeologia (Figura 2). O levantamento geofísico-estrutural foi desenvolvido numa escala regional e compreendeu: compilação de mapa geológico em escala 1:200.000 (BRASIL-DNPM, 1988) e interpretação de lineamentos, com base em imagem Landsat; levantamento de dados estruturais do terreno; análise de dados gravimétricos e execução de sondagens elétricas verticais (SEV) e longitudinais (SEL) (MEDEIROS et al., 2001). 


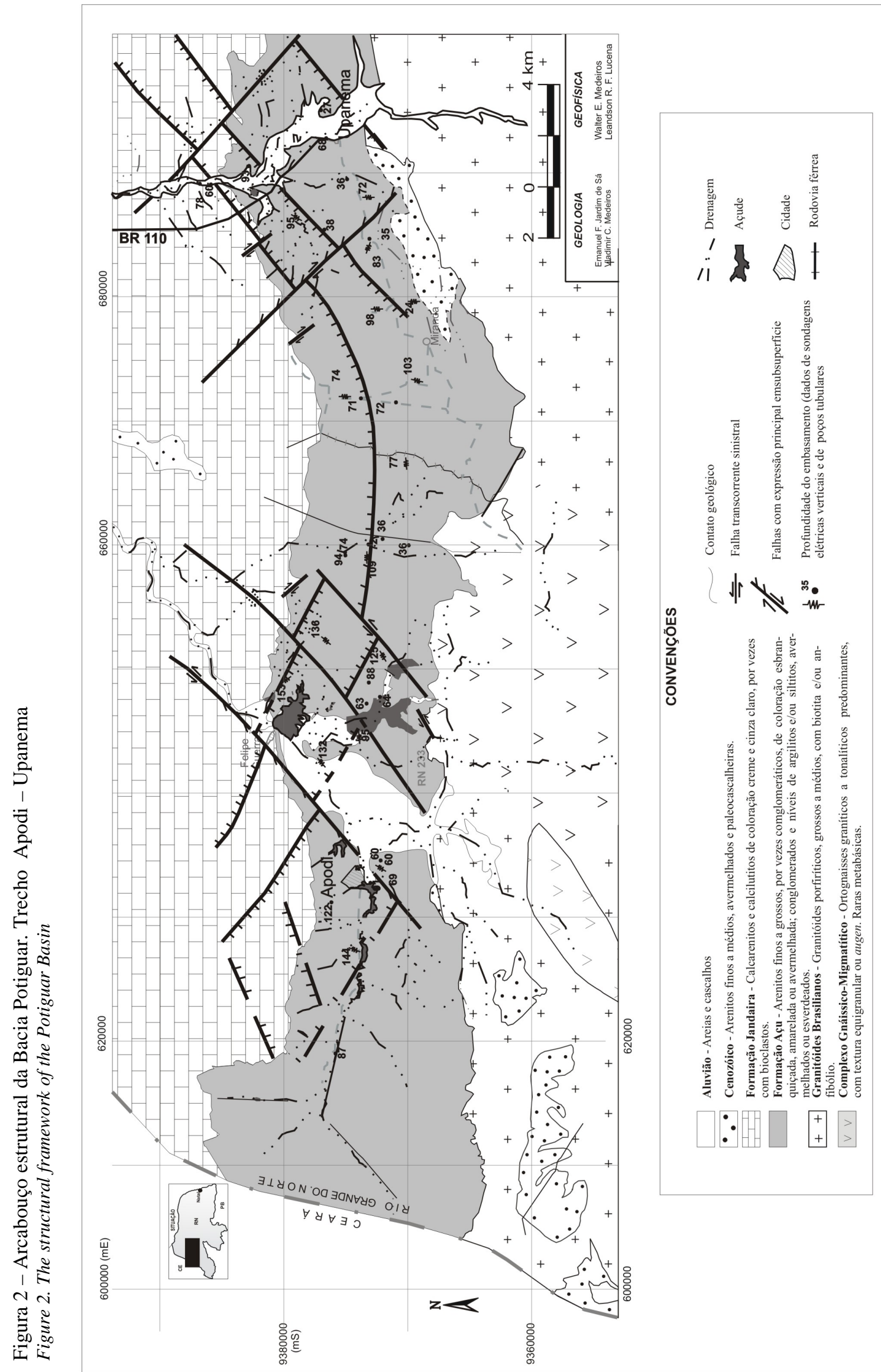


Denota-se no mapa geológico a presença de altos e baixos estruturais (Figuras 3A, 3B e 3C). As principais falhas com rejeitos verticais inferidos a partir dos dados geofísicos (geo-elétricos e gravimetria) e ou poços, situam-se próximas às estruturas que, em subsuperfície, são mapeadas pela PETROBRAS como limites do graben central. Embora algumas das anomalias (ou simplesmente "altos" e "baixos") também possam ser interpretadas como feições associadas a um paleorelevo, a configuração das isogálicas, o contraste entre as sondagens elétricas adjacentes, e os dados do terreno, favorecem uma interpretação estrutural (falhas) na maioria dos casos (MEDEIROS et al., 2001).

As figuras 4 e 5 apresentam iso-linhas de espessura da Formação Açu e de espessuras saturadas do aqüífero Açu (Fevereiro/2001), respectivamente, as quais foram obtidas com base nos dados do cadastramento de poços, nos perfis litológicos de poços (Tabela 1), e resultados de sondagens elétricas verticais segundo Medeiros et al. (2001) e sondagens elétricas longitudinais (SANTOS, 1977). Ver Tabela 2. Verifica-se que há um aumento das espessuras do aqüífero Açu no sentido de sul (embasamento cristalino) para norte (Formação Jandaira).

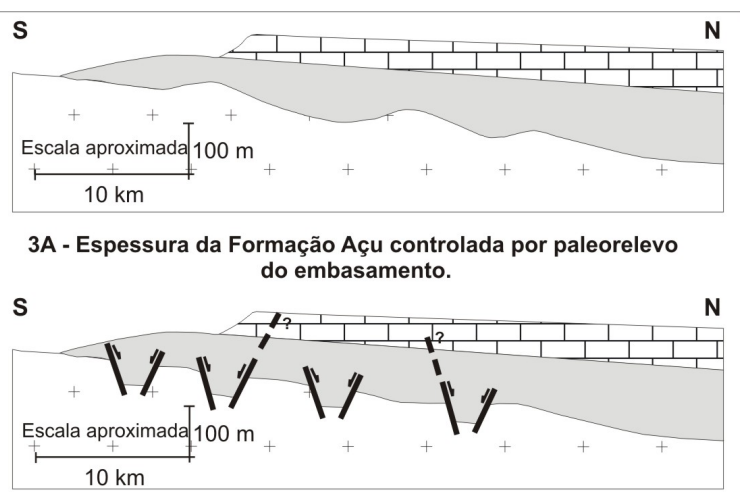

3B - Estruturas tipo graben preenchidas pela Formação Açu.

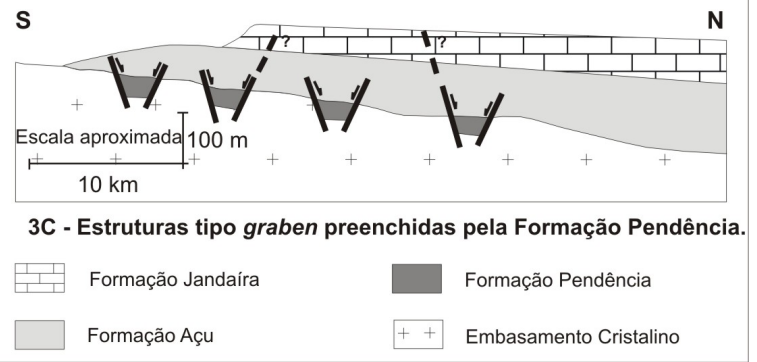

Figura 3. Modelos de condicionamento estruturalhidrogeológico na borda sudoeste da Bacia Potiguar. Fonte: MEDEIROS et. al. 2001.

Figure 3 - The hydrogeologic structural models on the border southwest of the Potiguar Basin. Authors: Medeiros et al. (2001)

A espessura da Formação Açu varia de menos de $10 \mathrm{~m}$ na faixa sul da área (próximo ao contato com o embasamento cristalino) a mais de $90 \mathrm{~m}$ na faixa norte (em direção aos calcários). A porção centro-norte da área é que desenvolve maiores espessuras, podendo atingir $275 \mathrm{~m}$ (sul de Felipe Guerra).

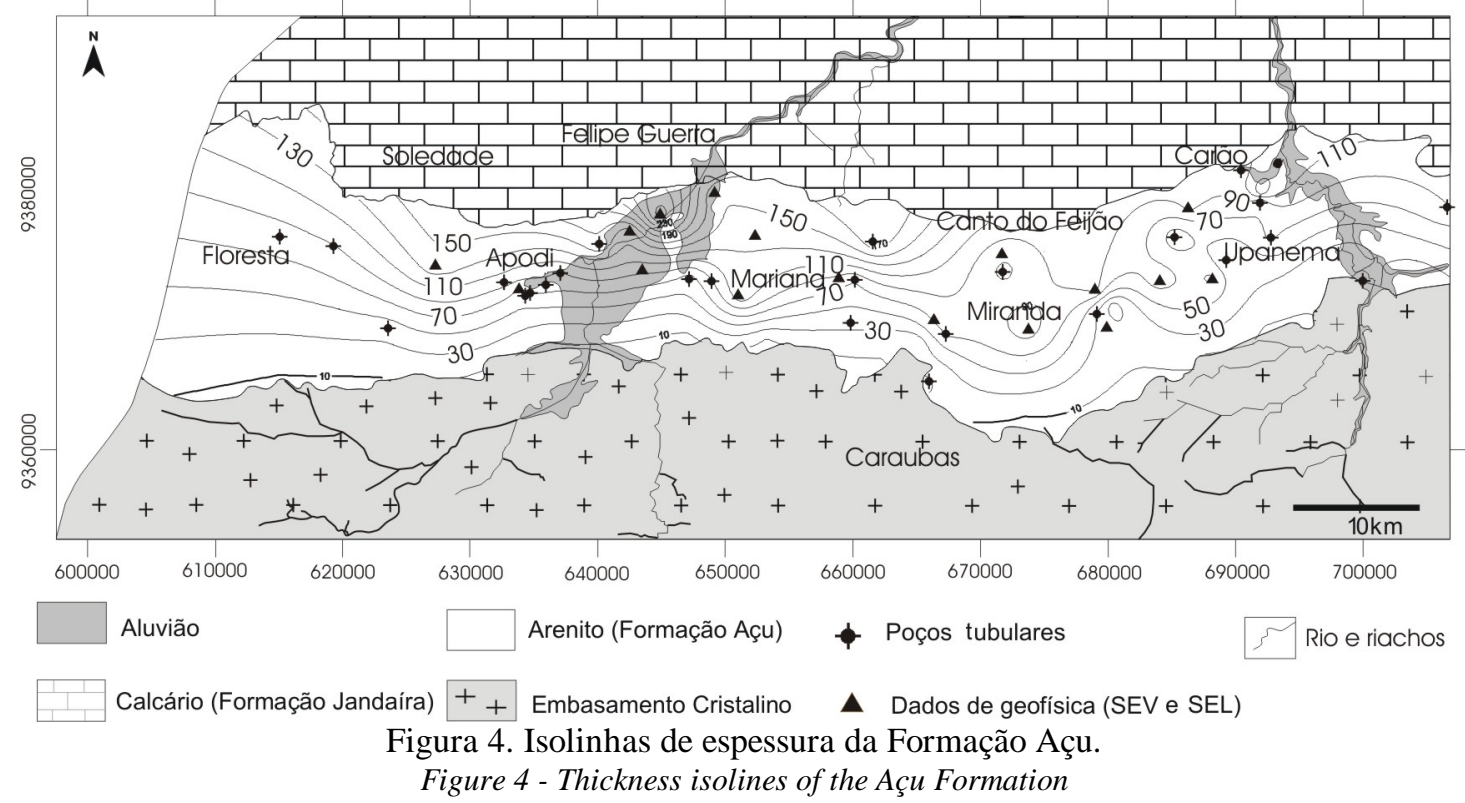




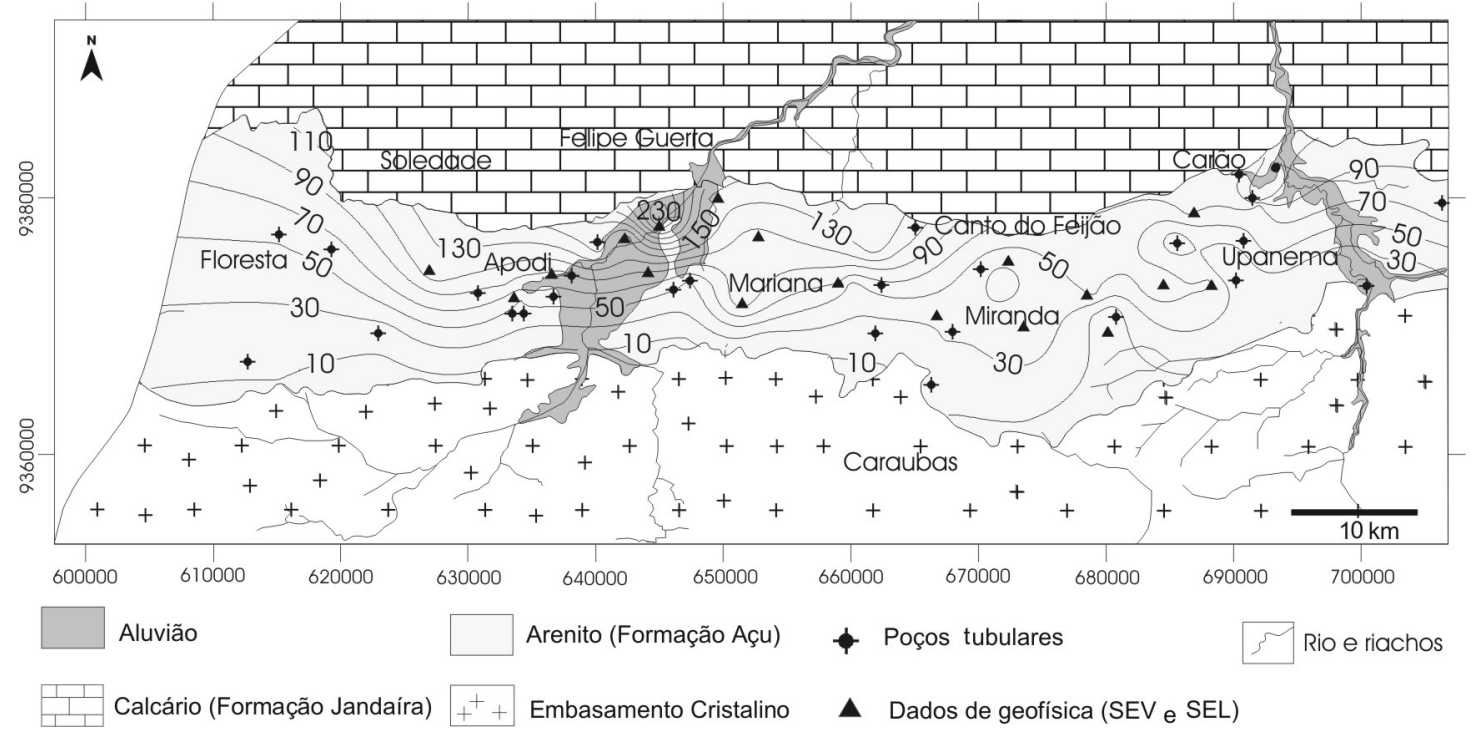

Figura 5. Espessura saturada do Aqüífero Açu.

Figure 5 - Saturated thickness of the Açu Aquifer.

Tabela 1 - Espessuras do aquífero Açu com base nos perfis litológicos

Table 1 - Thickness of the Açu aquifer obtained by geologic logs

\begin{tabular}{|c|c|c|c|c|c|}
\hline Poço & Localização & $\begin{array}{l}\text { Profundidade } \\
\text { poço } \\
(\mathbf{m})\end{array}$ & $\begin{array}{c}\text { Nível estático } \\
\text { (m) }\end{array}$ & $\begin{array}{c}\text { Espessura } \\
\text { penetrada }(\mathbf{m})\end{array}$ & $\begin{array}{c}\text { Espessura } \\
\text { saturada } \\
\text { penetrada }(\mathbf{m})\end{array}$ \\
\hline $\mathrm{P}-02^{*}$ & Missão & 93,00 & 3,00 & 91,00 & 89,00 \\
\hline$P-04$ & Córrego & 45,00 & 20,71 & 45,00 & 24,29 \\
\hline $\mathrm{P}-05$ & Córrego & 67,00 & 11,44 & 67,00 & 55,56 \\
\hline $\mathrm{P}-06$ & Retiro & 70,00 & 27,02 & 70,00 & 42,98 \\
\hline$P-07$ & Lagoa do Mato & 52,00 & 26,63 & 52,00 & 25,37 \\
\hline $\mathrm{P}-08$ & Lagoa do Mato & 90,00 & 29,26 & 90,00 & 60,74 \\
\hline $\mathrm{P}-09$ & Lagoa do Mato & 60,00 & 32,20 & 60,00 & 27,80 \\
\hline$P-10$ & Santa Isabel & 120,00 & 38,13 & 120,00 & 81,88 \\
\hline $\mathrm{P}-11$ & \begin{tabular}{|l} 
Saquinho \\
\end{tabular} & 102,00 & 38,80 & 102,00 & 63,20 \\
\hline $\mathrm{P}-12$ & Pé de Serra & 83,00 & 30,90 & 83,00 & 52,10 \\
\hline $\mathrm{P}-13$ & Tabuleiro Grande & 126,00 & 31,49 & 126,00 & 94,51 \\
\hline $\mathrm{P}-14$ & Tabuleiro Grande & 125,00 & 39,11 & 125,00 & 85,89 \\
\hline$P-15$ & Tabuleiro Grande & 125,00 & 23,53 & 125,00 & 101,47 \\
\hline $\mathrm{P}-16$ & Tabuleiro Grande & 118,00 & 19,68 & 118,00 & 98.32 \\
\hline $\mathrm{P}-17$ & Apodí & 90,00 & 28,10 & 90,00 & 61,90 \\
\hline $\mathrm{P}-18$ & Apodí & 100,00 & 38,15 & 100,00 & 61,85 \\
\hline$P-19$ & Apodí & 98,00 & 42,40 & 98,00 & 55.60 \\
\hline$P-20$ & Apodí & 106,00 & 30,00 & 106,00 & 76,00 \\
\hline$P-21$ & Apodí & 70,00 & 11,07 & 70,00 & 58,93 \\
\hline $\mathrm{P}-22$ & Pequé & 66.00 & 28,96 & 66,00 & 37,04 \\
\hline $\mathrm{P}-23^{*}$ & Bico Torto & 77,00 & 7,51 & 69,00 & 61,49 \\
\hline $\mathrm{P}-24^{*}$ & Bico Torto & 63,00 & 9,53 & 60,00 & 50,47 \\
\hline $\mathrm{P}-25$ & Apodí & 95,00 & 32,60 & 95,00 & 62,40 \\
\hline $\mathrm{P}-28$ & Ponta & 60,00 & 24,15 & 60,00 & 35,85 \\
\hline $\mathrm{P}-36^{*}$ & Lagoa do Mato & 90,00 & 27.58 & 87,00 & 59,42 \\
\hline $\mathrm{P}-52^{*}$ & Urbano & 31,00 & 11.99 & 30,00 & 18,01 \\
\hline$P-122$ & Tabuleiro Grande & 95,00 & 36,35 & 95,00 & 58,65 \\
\hline $\mathrm{P}-175^{*}$ & Baixa Fechada & 87,00 & 5,00 & 63,00 & 63,00 \\
\hline $\mathrm{P}-176^{*}$ & Baixa fechada & 111,30 & 5,00 & 82,00 & 82,00 \\
\hline $\mathrm{P}-177$ & \begin{tabular}{|l} 
Sítio Trapiá \\
\end{tabular} & 40,00 & 3,34 & 12,00 & 12,00 \\
\hline $\mathrm{P}-178$ & Sítio Juazeiro & 37,00 & 2,32 & 2,00 & 2,00 \\
\hline $\mathrm{P}-179^{*}$ & Sítio Juncal & 160,00 & 2,53 & 122,00 & 122,00 \\
\hline $\mathrm{P}-180$ & Sítio Rio Novo & 176,00 & 0,37 & 142,00 & 142,00 \\
\hline$P-186$ & Igarapé & 85,00 & 22,79 & 85,00 & 62,21 \\
\hline$P-189$ & Faz. São João & 104,00 & 19,62 & 104,00 & 84,38 \\
\hline $\mathrm{P}-205^{*}$ & Igarapé & 80,00 & 32,60 & 74,00 & 41,40 \\
\hline$P-206$ & Vertente & 98,00 & 59,10 & 98,00 & 38,90 \\
\hline$P-209$ & Igarapé & 142,00 & 26,12 & 142,00 & 115,88 \\
\hline
\end{tabular}


continuação

Tabela 1 - Espessuras do aqüífero Açu com base nos perfis litológicos

Table 1 - Thickness of the Açu aquifer obtained by geologic logs

\begin{tabular}{|c|c|c|c|c|c|}
\hline Poço & Localizaçãa & $\begin{array}{c}\text { Profundidade } \\
\text { poço } \\
\text { (m) }\end{array}$ & $\begin{array}{l}\text { Nível estático } \\
\text { (m) }\end{array}$ & $\begin{array}{c}\text { Espessura } \\
\text { penetrada }(m)\end{array}$ & $\begin{array}{c}\text { Espessura } \\
\text { saturada } \\
\text { penetrada }(\mathbf{m})\end{array}$ \\
\hline$P-211$ & Igarapé & 120.00 & 11,70 & 120,00 & 108,3 \\
\hline$P-221$ & Faz. Itaoca II & 79,00 & 14,69 & 79,00 & 64,31 \\
\hline$P-222$ & Faz. Itaoca III & 70,00 & 8,34 & 70,00 & 61,66 \\
\hline $\mathrm{P}-224$ & Faz. Itaoca & 120,00 & 11,70 & 120,00 & 108.30 \\
\hline $\mathrm{P}-227^{*}$ & Mariana & 91,00 & 21,10 & 88,00 & 66,90 \\
\hline $\mathrm{P}-229^{*}$ & Mariana & 65,00 & 16,33 & 64,00 & 47,67 \\
\hline$P-232$ & Santana & 92,00 & 8,04 & 92,00 & 83,96 \\
\hline $\mathrm{P}-232.1$ & Santana & 112,00 & 8,18 & 112,00 & 103,82 \\
\hline $\mathrm{P}-246^{*}$ & Quadro Cachoeira & 42,00 & 9,84 & 36,00 & 26,16 \\
\hline $\mathrm{P}-250$ & Faz.S. J. Arisco & 115,00 & 37,97 & 115,00 & 77,03 \\
\hline $\mathrm{P}-259$ & Faz. Dois Irmãos & 116.00 & 58,41 & 116,00 & 57,59 \\
\hline$P-268$ & $\mathrm{Km} 101$ & 120,00 & 58,40 & 120,00 & 61,60 \\
\hline$P-270$ & Km 101 & 92,00 & 72,69 & 92,00 & 19,31 \\
\hline $\mathrm{P}-271$ & Canto do Feijão & 100,00 & 20,65 & 100,00 & 79,35 \\
\hline $\mathrm{P}-285$ & Baixa Fechada & 100,00 & 39,67 & 100,00 & 60,33 \\
\hline $\mathrm{P}-287^{*}$ & Baixa Fechada & 75,00 & 42,22 & 72,00 & 29,78 \\
\hline $\mathrm{P}-289$ & Galho do Angico & 120,00 & 67,80 & 120,00 & 52,20 \\
\hline$P-294$ & Igarapé & 111.00 & 33.50 & 111,00 & 77.5 \\
\hline $\mathrm{P}-295$ & Igarapé & 107.20 & 27.86 & 107.20 & 79.34 \\
\hline$P-301$ & Sítio Independ. & 82.00 & 21.14 & 82,00 & 60.86 \\
\hline $\mathrm{P}-302^{*}$ & Barroca & 95.00 & 8.66 & 93,00 & 84.34 \\
\hline$P-304$ & Atoleiro & 88.00 & 12.30 & 88,00 & 75.70 \\
\hline$P-305$ & Independência & 95.00 & 13.10 & 95,00 & 81.90 \\
\hline $\mathrm{P}-310$ & Cabeça de Boi & 80.00 & 18.23 & 80,00 & 61.77 \\
\hline $\mathrm{P}-312$ & Boágua & 52.00 & 13.22 & 52,00 & 38.78 \\
\hline $\mathrm{P}-319$ & Carão & 100.00 & 11.58 & 100,00 & 88.42 \\
\hline $\mathrm{P}-323$ & Poré & 66.00 & 7.40 & 66,00 & 58.60 \\
\hline $\mathrm{P}-324$ & Poré & 60.00 & 10.75 & 60,00 & 49.25 \\
\hline $\mathrm{P}-326$ & Poré & 60.00 & 12.39 & 60,00 & 47.61 \\
\hline $\mathrm{P}-331^{*}$ & Upanema & 74.00 & 5.00 & 68,00 & 63,00 \\
\hline $\mathrm{P}-346$ & Sorocaba & 100.00 & 44.62 & 100,00 & 55.38 \\
\hline $\mathrm{P}-347$ & Sorocaba & 120.00 & 35.60 & 120,00 & 84.40 \\
\hline $\mathrm{P}-355^{*}$ & Baixa do Tatu & 60.00 & 28.90 & 35,00 & 6.60 \\
\hline $\mathrm{P}-356$ & Vermelha & 40.00 & 8.96 & 40,00 & 31.04 \\
\hline $\mathrm{P}-364^{*}$ & Olho Da água & 51.00 & 22.57 & 33,00 & 10.43 \\
\hline $\mathrm{P}-367$ & Galho de Angico & 120.00 & 66.73 & 120,00 & 53.27 \\
\hline $\mathrm{P}-370$ & Baixa do Feijão & 100.00 & 39.52 & 100,00 & 60.48 \\
\hline $\mathrm{P}-374$ & Canafístola & 90.00 & 16.00 & 90,00 & 74,00 \\
\hline $\mathrm{P}-381$ & Atoleiro & 88.00 & 12,30 & 88,00 & 75.70 \\
\hline $\mathrm{P}-400$ & S.B. Vermelha & 102,00 & 20.5 & 81.50 & 60.75 \\
\hline $\mathrm{P}-401$ & Livramento II & 108,00 & 13.52 & 94.48 & 80.96 \\
\hline$P-403^{*}$ & Baixa Grande & 80,00 & 47.70 & 79,00 & 31.30 \\
\hline $\mathrm{P}-404$ & Canto do Feijão & 92,00 & 51.00 & 92,00 & 41,00 \\
\hline$P-4705$ & Faz. Caraúbas & 154,00 & 13.89 & 86,00 & 86,00 \\
\hline $\mathrm{P}-407^{*}$ & Bom Lugar & 130,00 & 10,00 & 90,00 & 80,00 \\
\hline $\mathrm{P}-415^{*}$ & Vila Paraibana & 54,00 & 10,00 & 48,00 & 38,00 \\
\hline $\mathrm{P}-416^{*}$ & Pedra II & 45,00 & 18,20 & 45,00 & 26.80 \\
\hline $\mathrm{P}-418^{*}$ & Upanema & 76,00 & 10,00 & 75,00 & 65,00 \\
\hline$P-419$ & Igarapé & 80,00 & 33.10 & 80,00 & 46.90 \\
\hline $\mathrm{P}-420$ & Igarapé & 117,00 & 27.39 & 117,00 & 89.61 \\
\hline $\mathrm{P}-422$ & São Lourenço & 88,00 & 10.93 & 80,00 & 69.07 \\
\hline $\mathrm{P}-423$ & Faz. R. Pascoal & 110,00 & 8.48 & 110,00 & 101.52 \\
\hline$P-424$ & Miranda & 84,00 & 39.48 & 84,00 & 44.52 \\
\hline $\mathrm{P}-425$ & Zona Urbana F.G & 135,00 & 9.03 & 135,00 & 125.97 \\
\hline $\mathrm{P}-426$ & Igarapé & 101,00 & 41.75 & 101,00 & 59.25 \\
\hline $\mathrm{P}-427^{*}$ & Bela Fonte & 76,50 & 20.5 & 72,00 & 51,50 \\
\hline $\mathrm{P}-\mathrm{P}^{*}$ & Assentamento Caraúbas & 300,00 & 42,0 & 185,00 & 143,00 \\
\hline
\end{tabular}

Obs.: * Poços que atingem o embasamento (espessura total); P: Poços cadastrados; P - P: Poço PETROBRAS 
Tabela 2 - Espessuras do aqüífero Açu com base em prospecção geofísica Table 2. Thickness of the Açu aquifer obtained by geophysical prospection

\begin{tabular}{|c|c|c|c|c|}
\hline Ponto & Localização & $\begin{array}{c}\text { Nível estático } \\
(\mathbf{m})\end{array}$ & $\begin{array}{c}\text { Espessura } \\
(\mathbf{m})\end{array}$ & $\begin{array}{c}\text { Espessura saturada } \\
(\mathbf{m})\end{array}$ \\
\hline SEV 1 & Jatobá & 17,00 & 77,00 & 60,00 \\
\hline SEV 2 & Bx. do Feijão & 22,00 & 74,00 & 52,00 \\
\hline SEV 3 & Miranda & 32,50 & 102,00 & 69,50 \\
\hline SEV 4 & Bx. do Tatu & 12,00 & 72,00 & 60,00 \\
\hline SEV 5 & Vermelha & 27,50 & 82,00 & 54,50 \\
\hline SEV 6 & Retiro & 4,00 & 24,00 & 20,00 \\
\hline SEV 7 & Retiro & 13,00 & 98,00 & 85,00 \\
\hline SEV 8 & Pau d'arco & 5,00 & 95,00 & 90,00 \\
\hline SEV 9 & Bico Torto & 7,50 & 60,00 & 52,50 \\
\hline SEV 10 & Largo Apodi & 23,50 & 143,00 & 119,50 \\
\hline SEV 11 & São Lourenço & 6,00 & 132,00 & 126,00 \\
\hline SEV 12 & Paulista & 4,75 & 94,00 & 89,25 \\
\hline SEV 13 & Mato Verde & 3,00 & 153,00 & 150,00 \\
\hline SEV 14 & Ursulina & 5,00 & 125,00 & 120,00 \\
\hline SEV 15 & Aç. Nestor & 5,50 & 135,00 & 129,50 \\
\hline SEV 16 & Cachoeira & 19,00 & 109,00 & 90,00 \\
\hline SEL 44 & Felipe Guerra & 15,00 & 290,00 & 275,00 \\
\hline
\end{tabular}

Fonte: Medeiros et al., 2001 e Santos (1977).

Obs.: SEV: Sondagem Elétrica Vertical; SEL: Sondagem Elétrica Longitudinal.

O comportamento geral das espessuras saturadas do aqüífero Açu é similar (Figura 5), variando de menos de $10 \mathrm{~m}$ na faixa sul a mais de $70 \mathrm{~m}$ na faixa norte. Tal como ocorre com a espessura total da Formação Açu, a parte central da faixa norte é que desenvolve maiores espessuras saturadas, superiores a $130 \mathrm{~m}$, podendo chegar a $255 \mathrm{~m}$ ao sul de Felipe Guerra com base nos dados levantados. A espessura saturada média, no setor norte, é da ordem de 150 $\mathrm{m}$.

Tendo em vista uma melhor visualização e caracterização da estrutura hidrogeológica do terreno, foram elaboradas seções geológicas (figuras 6 a 9) baseadas nos perfis litológicos de poços segundo a direção S-N. Em todas as seções denota-se o aumento das espessuras do aqüífero Açu de sul para norte, podendo estas variações estar associadas a falhamentos verticais escalonados, tal como sugerem os estudos geofísicos. A seção da Figura 6 cruza a planície aluvial do Apodi na direção SW - NE, passando próximo a cidade de Apodi até Felipe Guerra. Apenas o poço P-180, com $176 \mathrm{~m}$, não penetra toda a espessura do aqüífero Açu. Verifica-se a ocorrência de depósitos aluviais cuja espessura atinge até $35 \mathrm{~m}$, formados por arenitos finos a grossos com intercalações argilosas. Com relação ao aqüífero Açu, há um domínio de sedimentos areno-argilosos próximo ao embasamento cristalino mudando para sedimentos finos e grossos, calcíferos, em direção aos calcários da Formação Jandaira, no setor norte. O topo do embasamento cristalino neste setor situa-se a profundidades superiores a $176 \mathrm{~m}$, o que equivale a dizer que a espessura do aquífero Açu é superior a $140 \mathrm{~m}$, já que os primeiros $36 \mathrm{~m}$ são compostos por sedimentos aluvionares.

Na seção da Figura 7, de direção SE-NW, apenas o poço P-23, com $69 \mathrm{~m}$, distanciado de 6 $\mathrm{km}$ do limite sul da área, atinge o embasamento cristalino. Nos demais poços, com profundidades que vão de 88 a $126 \mathrm{~m}$, o topo do embasamento não é atingido. Com relação a litologia, há um domínio de sedimentos mais grosseiros na parte mais inferior dos perfis, com a presença de arenitos argilosos nos níveis mais superiores. $\mathrm{Na}$ seção geológica da Figura 8 o topo do embasamento cristalino foi atingido a profundidades de 36 e $74 \mathrm{~m}$, a distâncias do limite sul da área de 3 e $8 \mathrm{~km}$, respectivamente. O poço $\mathrm{P}-209$, já próximo dos calcários, com 142 $\mathrm{m}$ de profundidade, não atingiu o embasamento rochoso. A correlação litoestratigráfica, neste caso, é muito difícil de ser estabelecida pela grande variação lateral de fácies, o que poderia estar associado a falhamentos ou na pior das hipóteses erros associados a descrição do perfil do poço p-209, o qual exibe um perfil formado de argilas próximo do poço P-294 cujo perfil encerra arenitos finos a grossos e é de boa produção (60 $\mathrm{m}^{3} / \mathrm{h}$ ). A seção geológica da Figura 9 situa-se próxima ao extremo leste da área do projeto, passando próximo a cidade de Upanema. $\mathrm{O}$ poço P-331 atingiu o embasamento cristalino a uma profundidade de $68 \mathrm{~m}$ e está distanciado de $7 \mathrm{~km}$ do limite sul da área. Com relação a litologia, com raras exceções o comportamento é similar as demais seções, com a ocorrência de sedimentos mais grossos nos níveis mais inferiores dos perfis. 


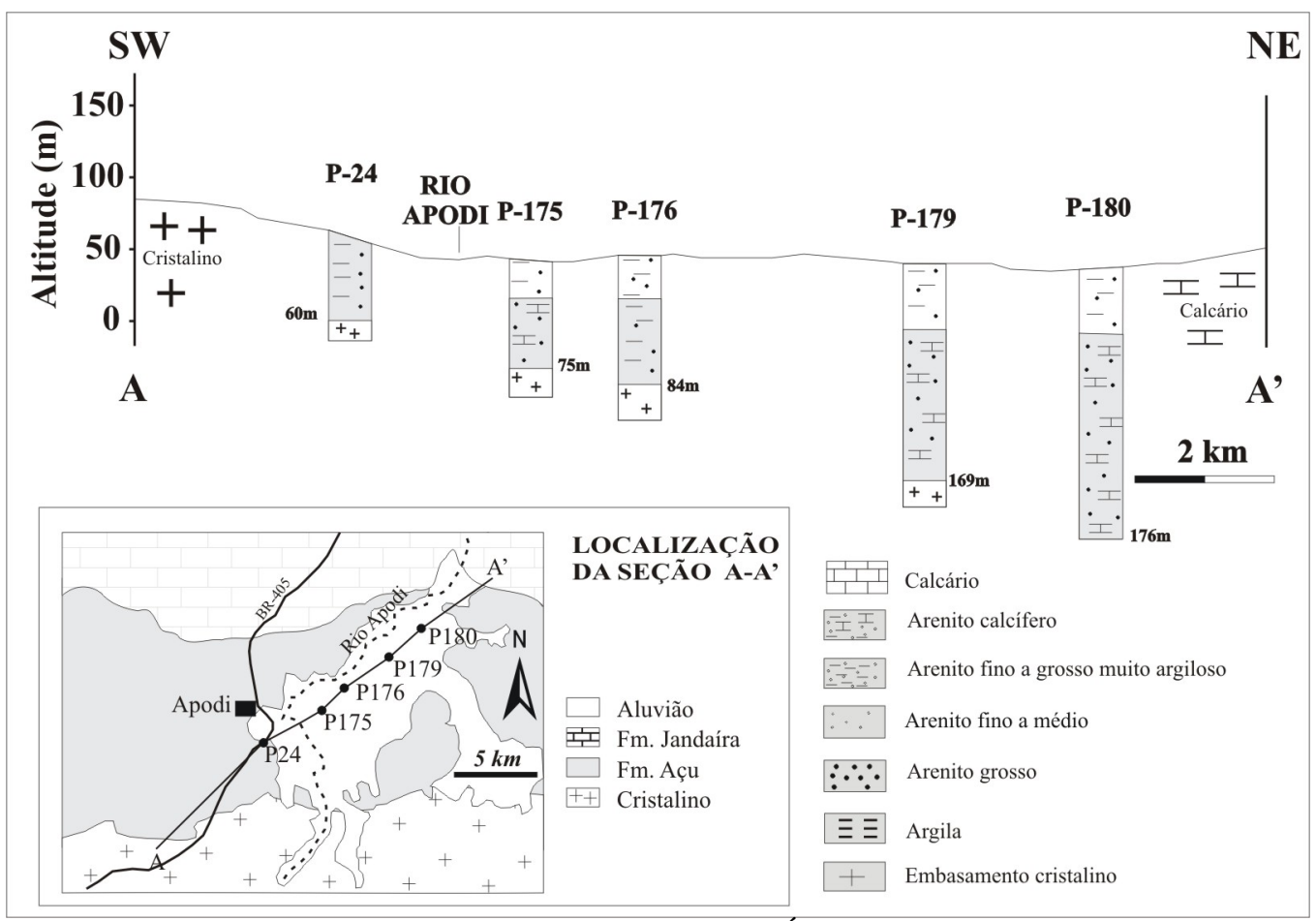

Figura 6. Seção geológica A-A', Área de Apodi.

Figure 6 - Geologic section A-A' (Apodi area).

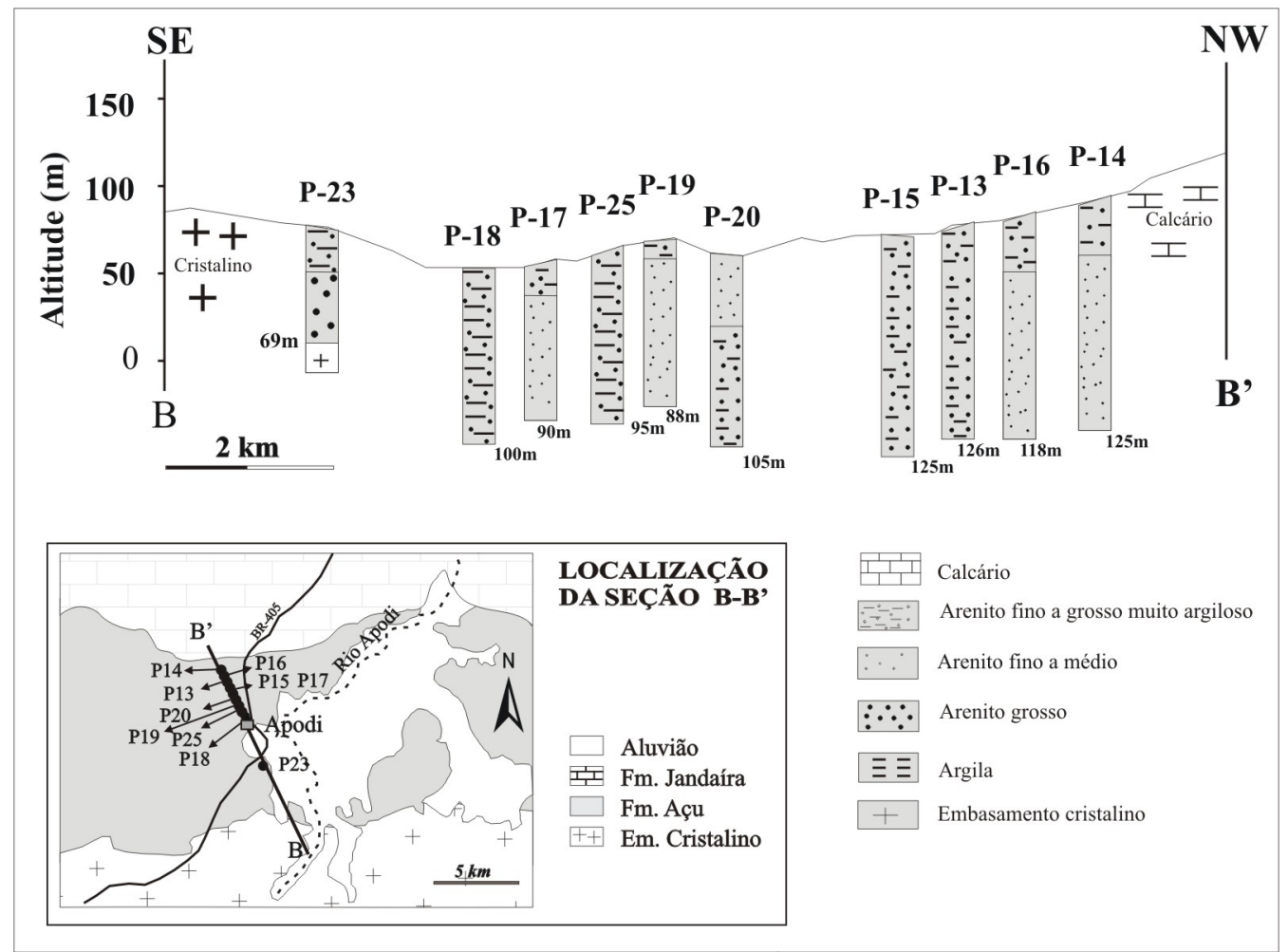

Figura 7. Seção geológica B-B', Área de Apodi.

Figure 7 - Geologic section B-B' (Apodi area). 


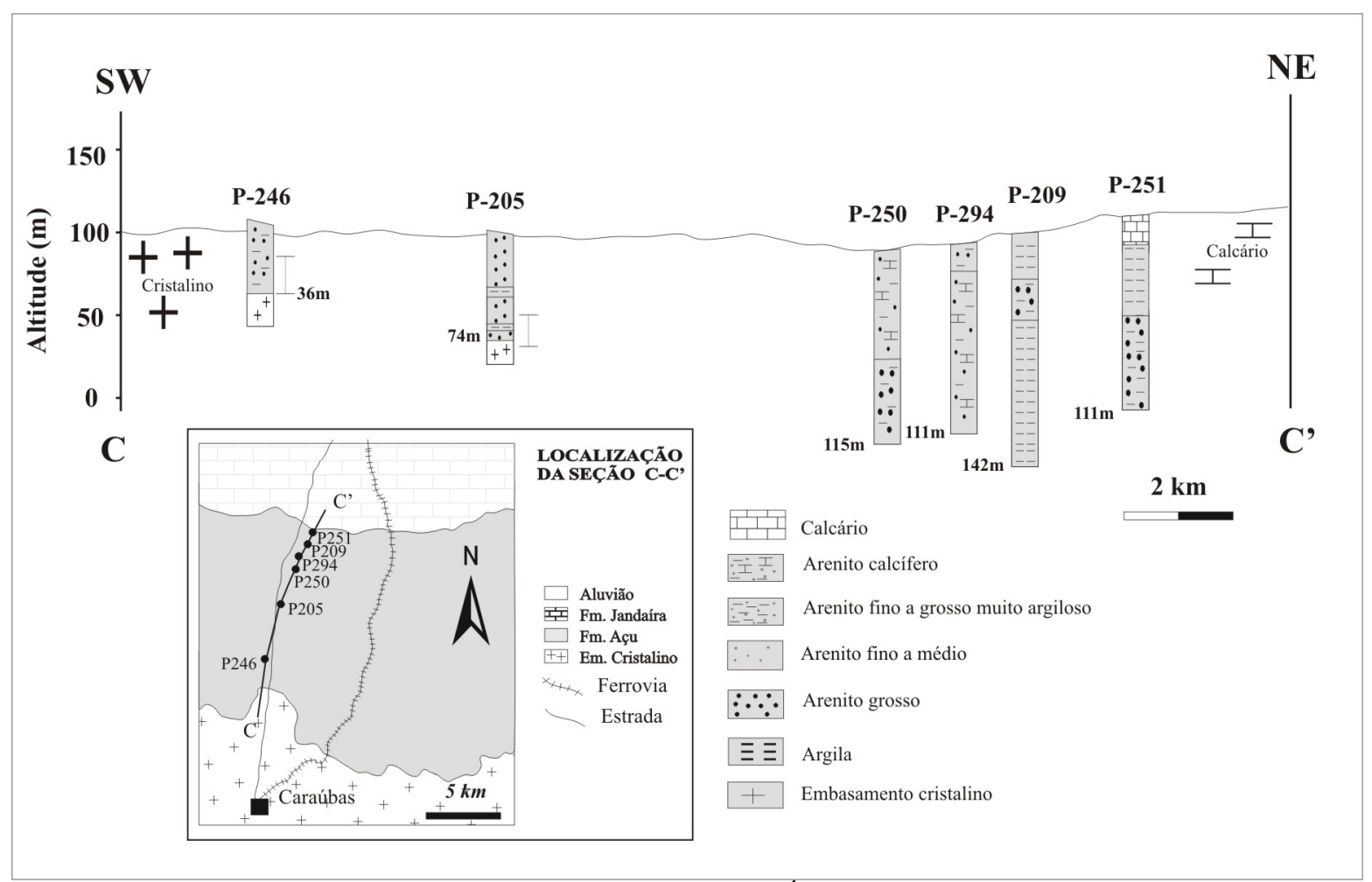

Figura 8. Seção geológica C-C', Área de Caraúbas Figure 8 - Geologic section C-C' (Caraúbas area)

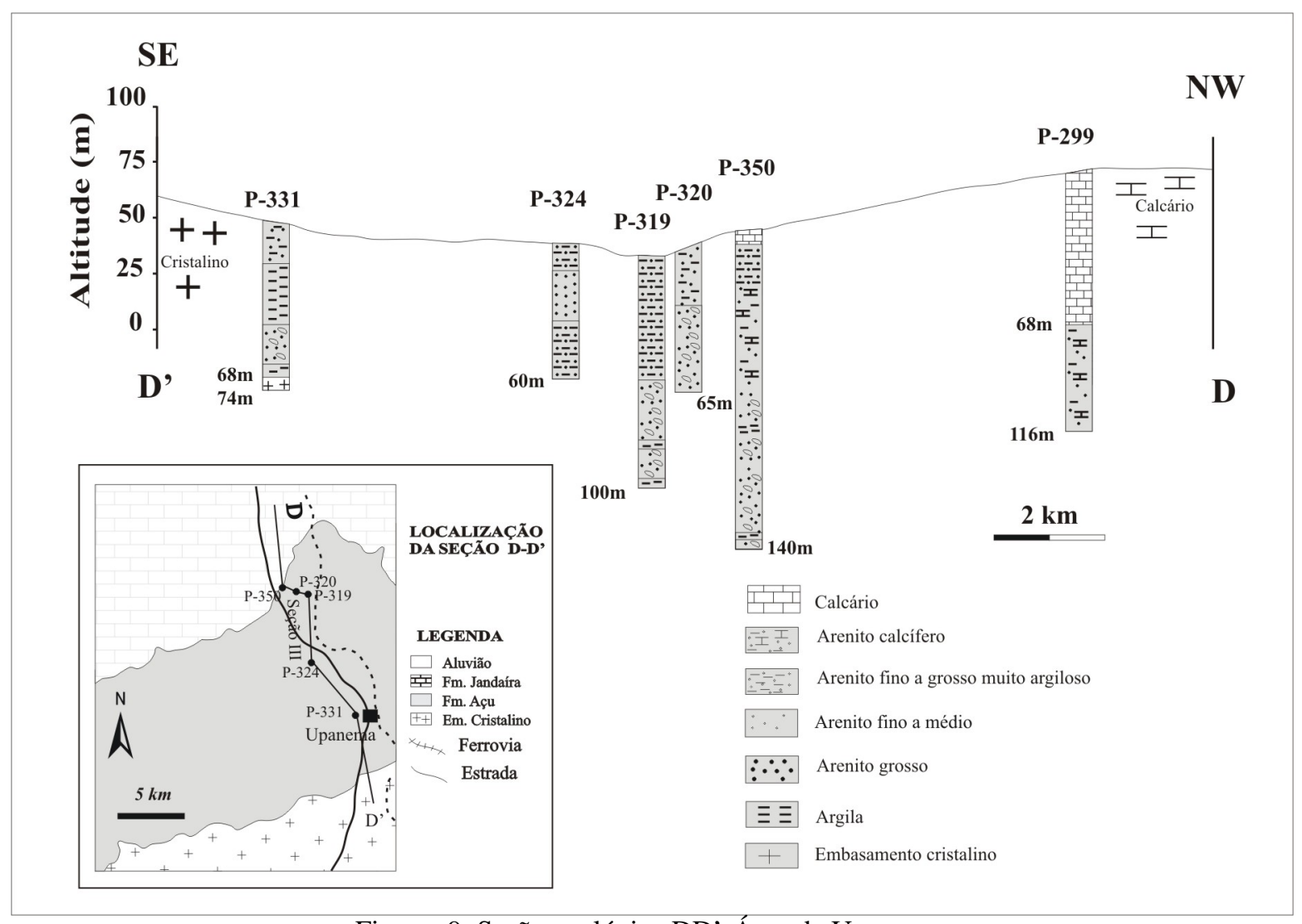

Figura 9. Seção geológica DD’-Área de Upanema. Figure 9 - Geologic section D-D" (Upanema area) 


\section{FLUXO SUBTERRÂNEO E PARÂMETROS HIDRODINÂMICOS}

De acordo com a configuração das equipotenciais (Figura 10), a estrutura geológica do terreno condiciona linhas de escoamento subterrâneo em geral orientadas no sentido de sul para norte, partindo do contato com as rochas cristalinas em direção aos domínios dos calcários da Formação Jandaira. Verificam-se ocasionalmente inflexões das linhas de escoamento para nordeste e noroeste em direção aos vales dos rios principais que drenam a área (rios Apodi e do Carmo).
As águas subterrâneas escoam na faixa sul da área com gradientes hidráulicos relativamente elevados, superiores a $1 \%$, enquanto que na faixa norte, contígua aos calcários, os gradientes são mais baixos, da ordem de $0,2 \%$, sugerindo melhores condições hidrogeológicas neste setor, o que na região da Planície do Apodi pode estar associado também a recarga propiciada pelo aqüífero aluvial em direção ao aqüífero Açu por drenança vertical descendente.

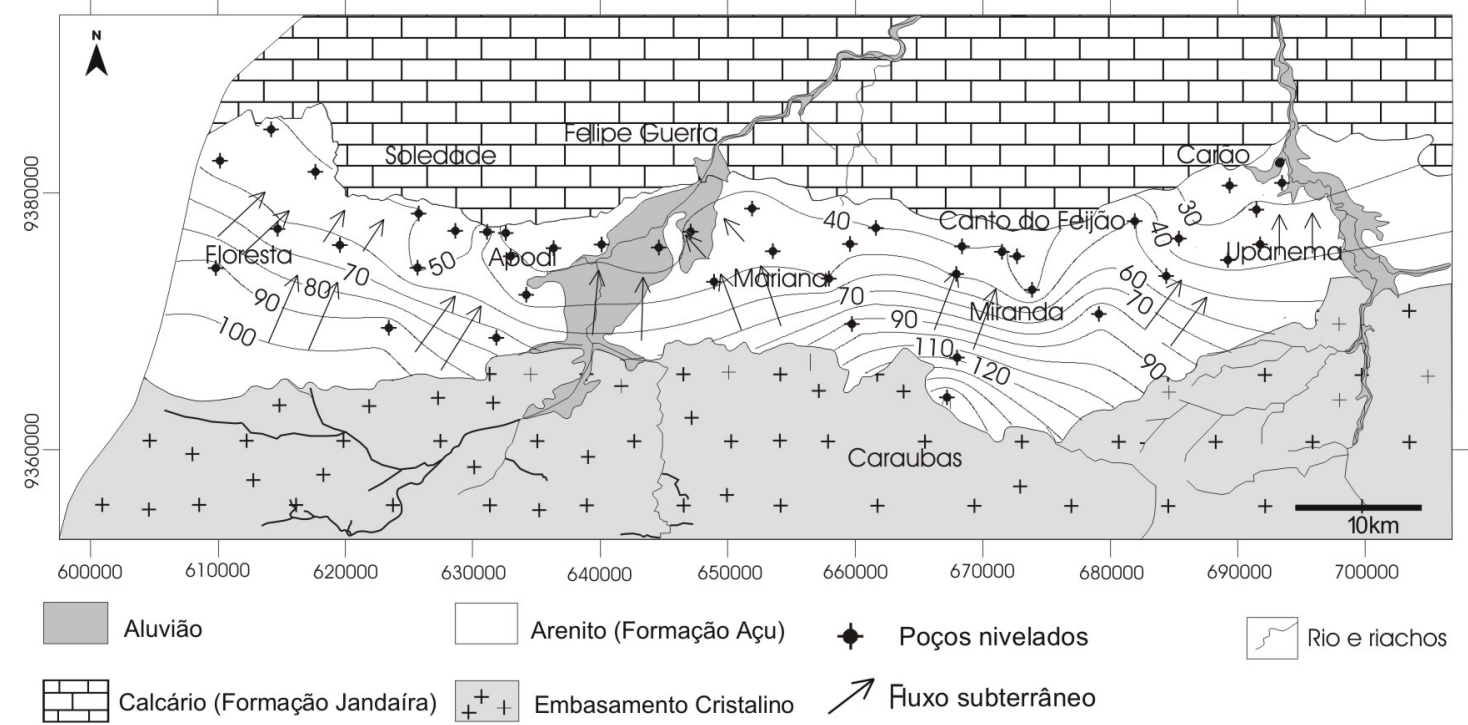

Figura 10. Potenciometria do aqüífero Açu.

Figure 10 - Potentiometric contour of the Açu Aquifer.

Os parâmetros hidrodinâmicos do aquífero Açu foram avaliados a partir da interpretação dos resultados de 41 testes de bombeamento em poços de produção (Tabela 3), cujos ensaios tiveram uma duração de no máximo 24 horas, com observação da recuperação dos níveis da água depois de encerrado os bombeamentos. 
Tabela 3 - Resumo do resultado dos testes de bombeamento e parâmetros hidrodinâmicos obtidos: Table 3. Summary of the pumping tests results and the hydrodinamics parameters.

\begin{tabular}{|c|c|c|c|c|c|c|c|c|c|}
\hline & Poço & $\begin{array}{c}\text { Prof. } \\
\text { (m) }\end{array}$ & $\begin{array}{l}\text { tb } \\
\text { (h) }\end{array}$ & $\begin{array}{l}\text { NE } \\
(\mathbf{m})\end{array}$ & $\begin{array}{l}\text { ND } \\
\text { (m) }\end{array}$ & $\begin{array}{c}\mathbf{S} \\
(\mathbf{m})\end{array}$ & $\begin{array}{c}\mathbf{Q} \\
\left(\mathbf{m}^{3} / \mathbf{h}\right)\end{array}$ & $\begin{array}{c}\mathbf{T} \\
\left(\mathrm{m}^{2} / \mathbf{d}\right)\end{array}$ & $\begin{array}{c}\mathbf{K} \\
(\mathbf{m} / \mathbf{d})\end{array}$ \\
\hline \multirow{9}{*}{ 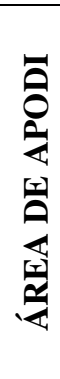 } & 15 & - & 10 & 24,7 & 36,5 & 11,8 & 68,7 & 194,4 & 2,5 \\
\hline & 16 & 118 & 12 & 19,7 & 42,3 & 22,6 & 63,7 & 168,5 & 2,1 \\
\hline & 28 & 60 & 12 & 21,7 & 28,4 & 6,7 & 7,00 & 33,9 & 1,0 \\
\hline & 400 & 102 & 12 & 20,5 & 30,0 & 9,5 & 3,3 & 6,0 & 0,1 \\
\hline & 421 & 84 & 8 & 8,5 & 17,7 & 9,2 & 26,7 & 199,6 & 2,9 \\
\hline & 422 & 77.5 & 12 & 10,9 & 15,0 & 4,1 & 7,4 & 63,5 & 1,2 \\
\hline & 423 & 110 & 8 & 8,5 & 21,5 & 13,0 & 11,2 & 11,4 & 3,3 \\
\hline & 425 & 130 & 24 & 9,0 & 22,7 & 13,7 & 16,0 & 74,6 & 0,8 \\
\hline & 427 & 77 & 12 & 20,7 & 33,6 & 12,9 & 8,5 & 20,0 & 0,4 \\
\hline \multirow{19}{*}{ 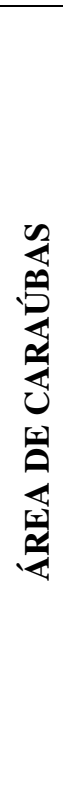 } & 182 & 96 & 6 & 20,3 & 26,6 & 6,3 & 4,8 & 5,3 & 0,1 \\
\hline & 186 & 85 & 12 & 24,0 & 44,5 & 20,5 & 21,9 & 8,6 & 0,1 \\
\hline & 205 & 80 & 6 & 32,0 & 56,2 & 24,2 & 2,5 & 1,1 & 0,04 \\
\hline & 209 & 142 & 8 & 29,9 & 42,0 & 12,1 & 8,7 & 19,2 & 0,8 \\
\hline & 232 & 92 & 12 & 9,3 & 20,6 & 11,3 & 10,8 & 20,7 & 0,4 \\
\hline & 232.1 & 112 & 12 & 10,6 & 45,8 & 35,2 & 20,3 & 18,8 & 0,3 \\
\hline & 250 & 115 & 12 & 39,9 & 50,8 & 10,9 & 26,2 & 84,0 & 1,7 \\
\hline & 265 & 116 & 12 & 63,8 & 65,8 & 2,0 & 1,5 & 11,4 & 0,2 \\
\hline & 270 & 92 & 12 & 51,0 & 63,8 & 12.8 & 3,5 & 4,0 & 0,1 \\
\hline & 285 & 100 & 24 & 40,5 & 49,3 & 8,8 & 30,0 & 170.2 & 3,7 \\
\hline & 294 & 111 & 12 & 29,2 & 44,3 & 15,1 & 36,0 & 115,7 & 1,6 \\
\hline & 295 & 112 & 12 & 22,9 & 36,3 & 13,4 & 37,0 & 128,7 & 1,8 \\
\hline & 401 & 108 & 12 & 13,5 & 27,7 & 14,2 & 7.0 & 12,1 & - \\
\hline & 403 & 80 & 12 & 47,7 & 62,1 & 14.4 & 0,4 & 0,9 & 0.03 \\
\hline & 404 & 92 & 12 & 51,0 & 63,3 & 12.3 & 3,4 & 3,9 & 0,1 \\
\hline & 419 & 80 & 9 & 33,2 & 47,3 & 14,1 & 13.3 & 29.6 & 0,8 \\
\hline & 420 & 115 & 18 & 27,4 & 30,5 & 3,1 & 6,7 & 129.6 & 1,6 \\
\hline & 424 & 84 & 12 & 39,5 & 43,9 & 4,4 & 3,6 & 16.4 & 0,6 \\
\hline & 428 & 85 & 12 & 21,2 & 27,0 & 5,8 & 6,5 & 18,1 & 0,3 \\
\hline \multirow{13}{*}{ 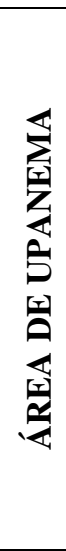 } & 429 & - & 12 & 42,1 & 44,5 & 2,4 & 26,2 & 99,4 & 2,5 \\
\hline & 302 & 95 & 12 & 8,7 & 20,0 & 11,3 & 15,4 & 113,2 & 1,7 \\
\hline & 318 & - & 12 & 5,8 & 6,2 & 0,4 & 12,9 & 114,0 & 1,3 \\
\hline & 319 & 100 & 12 & 5,3 & 36,0 & 30,7 & 25,7 & 82,4 & 1,0 \\
\hline & 326 & 60 & 11 & 11,4 & 23,5 & 12,1 & 5.6 & 14,4 & 0,3 \\
\hline & 345 & 84 & 10 & 35,7 & 45.9 & 10,2 & 3.45 & 61,2 & 1,4 \\
\hline & 346 & 100 & 24 & 44,6 & 50,9 & 6,3 & 4,5 & 8,4 & 0,3 \\
\hline & 347 & 120 & 24 & 35,3 & 37,9 & 2,6 & 9,0 & 89,0 & 2,2 \\
\hline & 350 & 142 & 8 & 15,0 & 16,7 & 1,7 & 9,1 & 140,8 & 1,3 \\
\hline & 356 & 40 & 24 & 4,00 & 24,9 & 20,9 & 1,7 & 0,9 & - \\
\hline & 370 & 100 & 24 & 40,5 & 49,3 & 8,8 & 30,0 & 165,9 & 3,5 \\
\hline & 387 & - & 12 & 9,5 & 12,3 & 2,8 & 12,9 & 140,8 & 1,6 \\
\hline & 392 & 52 & 12 & 13,2 & 20,3 & 7,1 & 5,8 & 18,3 & 0,5 \\
\hline
\end{tabular}

tb: tempo de bombeamento ; s: rebaixamento; T: transmissividade; NE: nível estático ; Q: vazão; K: condutividade hidráulica; ND: nível dinâmico

Os locais dos ensaios não estão distribuídos regularmente, o que seria o desejável; como também áreas importantes do ponto vista hidrogeológico não foram testadas. Apesar destas limitações, os ensaios permitiram boas estimativas da transmissividade e da condutividade hidráulica. A porosidade efetiva não chegou a ser avaliada, já que o único teste de bombeamento com dispositivo de poço de observação realizado teve curta duração e não ficou caracterizado o fenômeno de drenagem retardada na curva de rebaixamento com o tempo. Os testes foram interpretados pela aplicação dos métodos de Cooper \& Jacob para rebaixamento e Jacob-Theis para os dados de recuperação. Na maioria dos casos, a correção de Jacob para aquíferos livres foi aplicada aos dados de rebaixamento. A distribuição espacial da transmissividade é apresentada na Figura 11, na qual pode se observar que a transmissividade 
cresce no sentido de sul para norte na direção do fluxo subterrâneo, atingindo os valores mais elevados próximo ao contato com os calcários. No setor sul da área a transmissividade é inferior a $10 \mathrm{~m}^{2} / \mathrm{d}$ e no setor norte este parâmetro atinge valores superiores a $170 \mathrm{~m}^{2} / \mathrm{d}$ (oeste de Felipe Guerra).

A condutividade hidráulica tem um comportamento similar a transmissividade, ou seja, cresce no sentido de sul para norte. Na faixa meridional da área o aqüífero Açu apresenta valores de condutividade hidráulica inferior a 0,2 $\mathrm{m} / \mathrm{d}$, enquanto que na sua faixa setentrional este parâmetro assume valores em média de 1,86 m/d.

Os valores de transmissividade do setor norte da área foram obtidos com base em resultados de testes de bombeamento em poços com penetração parcial no aqüífero Açu. Para condições de penetração total, tomando por base a espessura saturada média de $150 \mathrm{~m}$ (obtida com base em sondagens mecânicas e sondagens geofísicas) e a condutividade hidráulica média de $1,86 \mathrm{~m} / \mathrm{d}$, verifica-se que a transmissividade do aqüífero Açu pode atingir valores estimados da ordem de $280 \mathrm{~m}^{2} / \mathrm{d}$, em média.

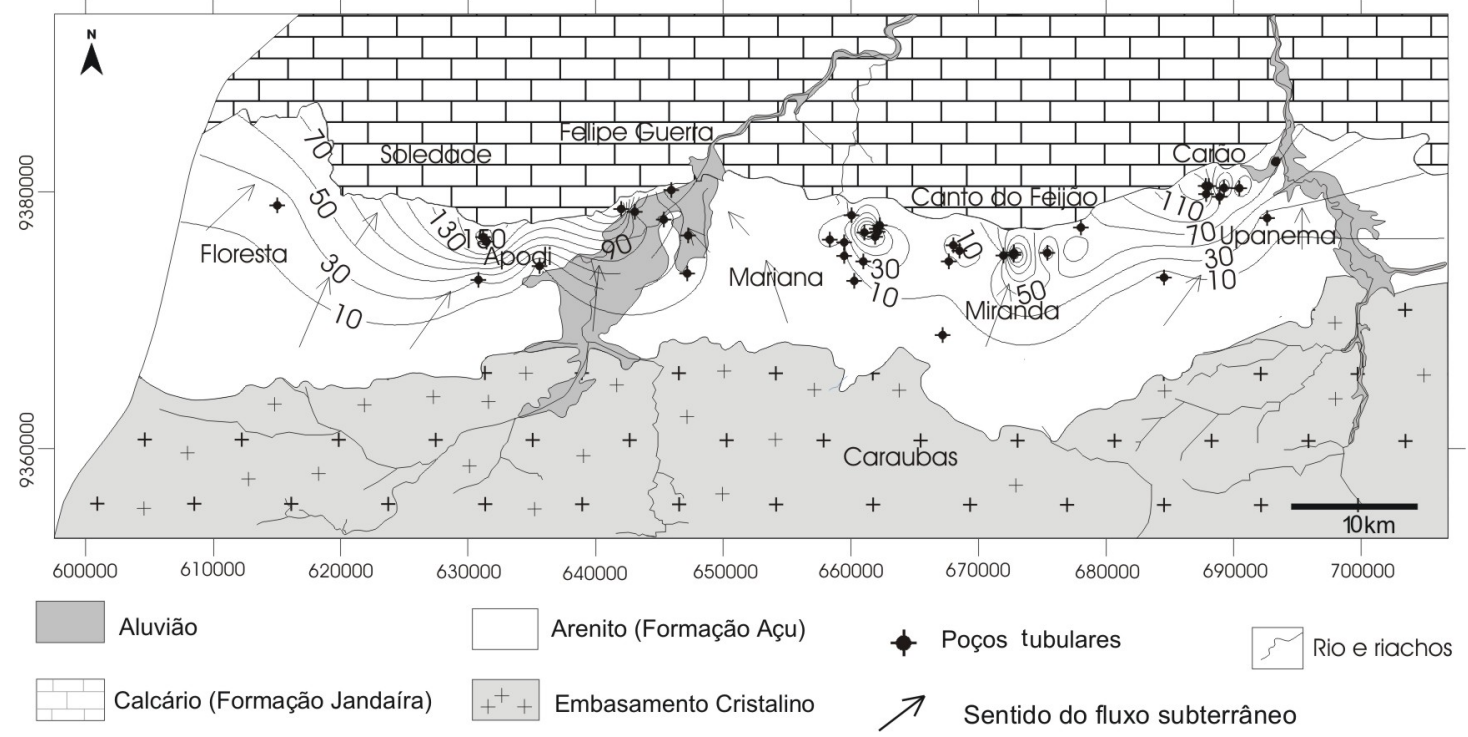

Figura 11. Transmissividade do aqüífero Açu.

Figure 11 - Transmissivity of the Açu aquifer.

\section{RECARGA DAS ÁGUAS SUBTERRÂNEAS}

A recarga das águas subterrâneas pode ser definida no senso geral como o fluxo de água descendente que alcança o nível da água de um aquífero livre, formando uma reserva de água adicional para as águas subterrâneas. A quantificação da recarga das águas subterrâneas é um pré-requisito básico para um eficiente manejo dos recursos de águas subterrâneas, e é particularmente vital em regiões semi-áridas onde tais recursos são freqüientemente a chave do desenvolvimento econômico. Nestas condições, em regiões semi-áridas a necessidade de estimativa de uma recarga confiável é fundamental (SIMMERS, 1997). Este parâmetro é, entretanto, muito difícil de ser avaliado principalmente em regiões semi-áridas (LERNER et. al., 1990; SIMMERS et al., 1997; LERNER, 1997; HEALY; COOK, 2002; SANFORD, 2002 e VRIES; SIMMERS, 2002). A recarga das águas subterrâneas pode ocorrer naturalmente das precipitações, rios, canais e como um fenômeno induzido pelo homem através de atividades de irrigação e de urbanização. A maioria das técnicas de avaliação de recarga em meio insaturado fornece estimativas pontuais, enquanto que as técnicas na zona saturada comumente integram áreas muito mais extensas. Ainda, enquanto as abordagens na zona insaturada fornecem estimativas potenciais da recarga, as abordagens na zona saturada fornecem evidências da recarga real porque a água alcança o nível da água (SCANLON; COOK, 2002). Devido as incertezas associadas com as técnicas para a estimativa da recarga, o uso de diferentes métodos é recomendado para que se possa comparar resultados e se chegar a um número mais confiável.

$\mathrm{Na}$ área de estudo a recarga das águas subterrâneas se processa principalmente pelas infiltrações diretas das águas de precipitação pluviométrica no terreno. Em menor escala, a recarga pode ocorrer no leito dos rios através dos aluviões. O processo de recarga em geral é dificultado pelas condições de aridez da área, que lhe atribui "déficit" hídrico expressivo; pelo 
caráter areno-argiloso da parte superior da Formação Açu e pela elevada profundidade do nível das águas subterrâneas na maior parte dos casos (Figura 12). Sabe-se que em situações similares de litologia do meio poroso insaturado, quanto maior a profundidade do nível freático maior será o tempo de trânsito das águas de infiltração às águas subterrâneas, o que, por conseguinte, pode influenciar na recarga efetiva. A profundidade do nível das águas subterrâneas em grande parte da área é superior a $30 \mathrm{~m}$, chegando a $110 \mathrm{~m}$ no seu extremo Noroeste. Os níveis das águas subterrâneas próximas ao contato com o embasamento cristalino e no domínio das planícies aluviais, entretanto, são inferiores a $10 \mathrm{~m}$.

No presente trabalho foram aplicadas diferentes metodologias na avaliação da recarga das águas subterrâneas, conforme apresentado a seguir e sintetizado na Tabela 4.

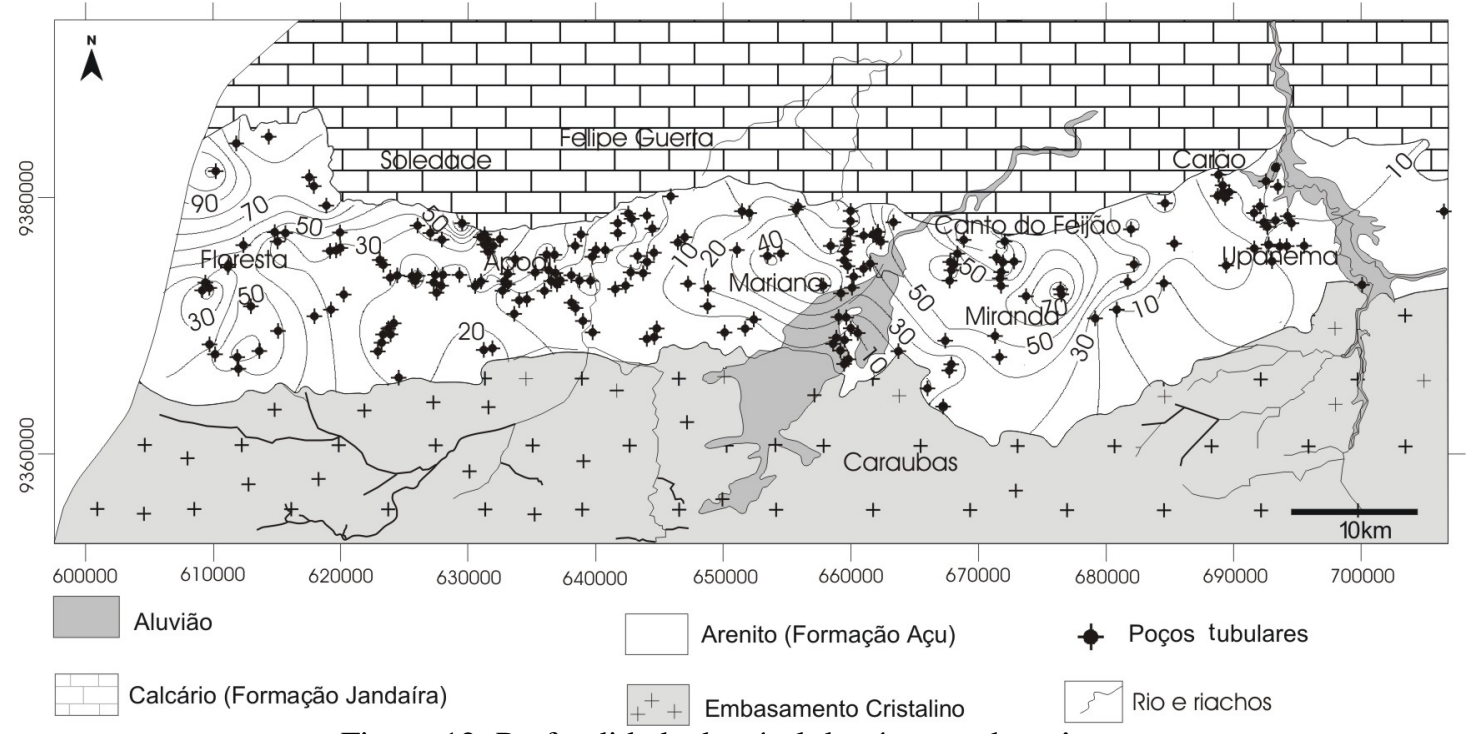

Figura 12. Profundidade do nível das águas subterrâneas.

Figure 12 - Groundwater level depth.

\section{Balanço hidroclimatológico}

$\mathrm{O}$ método do balanço hidroclimatológico é um procedimento elementar que pode fornecer uma primeira indicação potencial sobre o montante da recarga das águas subterrâneas. A equação geral do balanço hídrico estabelece que:

$$
\mathrm{P}=\mathrm{E}+\mathrm{R}+\mathrm{I}
$$

Onde $P$ é a precipitação (mm); E é a evapotranspiração real $(\mathrm{mm}) ; R$ é o escoamento superficial $(\mathrm{mm})$ e I é a infiltração $(\mathrm{mm})$.

$\mathrm{O}$ excedente anual de água no solo de precipitação $(\mathrm{R}+\mathrm{I})$ pode corresponder à lâmina de água infiltrada no terreno (CASTANY, 1975; FETTER, 1994). O excedente de água de precipitação obtida no balanço hídrico foi de 47,6 $\mathrm{mm}$, o qual pode corresponder à recarga das águas subterrâneas na área de estudo. Considerando que a precipitação pluviométrica média anual na área é de $765 \mathrm{~mm}$, a taxa de infiltração correspondente é de $6,20 \%$. O volume de água anual infiltrado em termos potenciais pode chegar a $62,83 \times 10^{6} \mathrm{~m}^{3}$.

\section{Aplicação da Ley de Darcy}

Em aquífferos livres, como é o caso do aquiífero Açu, suas potencialidades estão condicionadas principalmente as infiltrações diretas das águas de chuva, cujo volume efetivamente infiltrado restitui as reservas de águas subterrâneas que se perdem nos escoamentos naturais e explotação por poços e, também, alimentam o fluxo subterrâneo. Por definição, em condições de equilíbrio, sem considerar a explotação por poços, a infiltração eficaz é equivalente a vazão do fluxo subterrâneo natural. A descarga do fluxo subterrâneo natural em direção à região dos calcários, obtida a partir do mapa potenciométrico (Figura 10), foi de $1,688 \mathrm{~m}^{3} / \mathrm{s}$, o que equivale a $50,64 \times 10^{6} \mathrm{~m}^{3} / \mathrm{ano}$, que em termos de lâmina de água corresponde a $38 \mathrm{~mm}$. A equação utilizada foi:

$$
\mathrm{Q}=\mathrm{TIL}
$$

Onde $Q$ é a vazão do fluxo subterrâneo $\left(\mathrm{m}^{3} / \mathrm{s}\right) ; T$ é a transmissividade $\left(\mathrm{m}^{2} / \mathrm{s}\right)$; e L é a frente de escoamento $(\mathrm{km})$.

Nas avaliações foi considerado um valor médio de transmissividade de $3 \times 10^{-3} \mathrm{~m}^{2} / \mathrm{s}$, obtido a partir da condutividade hidráulica média de $2,31 \times 10^{-5} \mathrm{~m} / \mathrm{s}$ e espessura saturada de $130 \mathrm{~m}$ do aquífero Açu na faixa contígua aos calcários. A vazão do fluxo subterrâneo foi avaliada para uma 
condição no qual o aqüífero estava sendo explotado, e assim sendo, o montante correspondente a

esta explotação deve ser considerado na recarga anual, o que corresponde a $8,0 \times 10^{6} \mathrm{~m}^{3} / \mathrm{ano}$ (equivalente a $6 \mathrm{~mm} /$ anuais). A recarga de água subterrânea, neste caso, será o somatório da vazão de fluxo obtida com o correspondente volume anual explotado, ou seja, 58,64 x $10^{6}$ m3/ano ou $44 \mathrm{~mm}$ de lâmina de água infiltrada. A taxa de infiltração, portanto é da ordem de $5,7 \%$, tomando por base a precipitação pluviométrica média de 765,10 mm/ano.

\section{Flutuação sazonal do nível da água}

O método da flutuação do nível da água é baseado na premissa de que a elevação do nível da água subterrânea em aquíf́eros livres é devido a água de recarga que chega ao aquífero. A recarga é calculada como:

$$
\mathrm{R}=\mathrm{Sy}(\mathrm{dh} / \mathrm{dt})=\operatorname{Sy}(\Delta \mathrm{h} / \Delta \mathrm{t})
$$

Onde $S_{y}$ é a porosidade específica (adm); h é a altura do nível da água (mm), e té o tempo (s).

O método da flutuação de nível da água tem sido usado em vários estudos (RASMUSSEN; ANDREASEN, 1959; GERHARD, 1986; HALL; RISSER, 1993) e descrita em detalhe por HEALY; COOK (2002). As dificuldades de aplicação do método é atribuída em geral a falta de um conhecimento mais preciso da porosidade efetiva do material aquífero sujeito a variação sazonal, o qual não foi avaliado no presente trabalho. Quanto a variação do nível da água, as observações efetuadas não foram suficientes para uma caracterização adequada de $\Delta \mathrm{h}$, impossibilitando, portanto a aplicação do método da flutuação do nível da água.

\section{Balanço de cloreto}

A recarga das águas subterrâneas pode ser avaliada de forma aproximada pelo método do balanço do íon cloreto, o qual pode ser estabelecido pela equação:

$$
\mathrm{IC}_{\mathrm{i}}=\mathrm{PC}_{\mathrm{p}} \text {, ou seja, } \mathrm{I}=\mathrm{PC}_{\mathrm{p}} / \mathrm{C}_{\mathrm{i}}
$$

Onde I é a lâmina de água infiltrada (mm/ano); $C_{i}$ é a concentração de cloreto nas águas subterrâneas $(\mathrm{mg} / \mathrm{L}) ; \mathrm{P}$ é a precipitação pluviométrica ( $\mathrm{mm} / \mathrm{ano}$ ); e $\mathrm{C}_{\mathrm{p}}$ é a concentração de cloreto na água de chuva (mg/L).

Esse método baseia-se no fato de que o íon cloreto é conservativo e não sofre modificações durante a infiltração. Os resultados do balanço do íon cloreto são bons em zonas áridas e zonas arenosas, porém não tanto em zonas úmidas ou com elevado escoamento superficial (CUSTÓDIO, 1973 e CUSTÓDIO; LLAMAS, 1976). A concentração de cloreto nas águas subterrâneas do aquífero Açu, considerada para efeito de cálculo, corresponde ao valor representativo da faixa norte da área onde as águas estão mais diluídas e menos afetadas por processos de salinização, cujo teor de cloreto é de $50 \mathrm{mg} / \mathrm{L}$; no caso das águas de chuva, foi tomado o valor médio de $2,53 \mathrm{mg} / \mathrm{L}$. Desde que a precipitação pluviométrica na área é de 765,1 $\mathrm{mm} /$ ano, aplicando a equação do balanço de cloreto resulta uma lâmina de água infiltrada de $38,71 \mathrm{~mm}$, que corresponde a uma taxa de infiltração de 5,06\%.

Tabela 4. Recarga das águas subterrâneas

Tabela 4. Groundwater recharge

\begin{tabular}{|c|c|c|c|}
\hline Método & Balanço Hídrico & Lei de Darcy & Balanço de cloreto \\
\hline Lâmina de água infiltrada (mm/ano) & 47,60 & 44,00 & 38,71 \\
\hline Taxa de infiltração (\%) & 6,20 & 5,70 & 5,06 \\
\hline Volume infiltrado $\left(10^{6} \mathrm{~m}^{3} / \mathrm{ano}\right)$ & 62,83 & 58,64 & 51,08 \\
\hline
\end{tabular}

A recarga das águas subterrâneas do aquífero Açu a ser considerada neste trabalho corresponde à média obtida pela aplicação da Lei de Darcy e pelo Balanço de cloreto, ou seja, é da ordem de $41 \mathrm{~mm} /$ ano ou 54 milhões de $\mathrm{m}^{3} /$ ano. Portanto, não foi considerado o método do balanço hidroclimatológico o qual fornece apenas uma indicação potencial da recarga.

\section{CONDIÇÕES DE EXPLOTAÇÃO DAS ÁGUAS SUBTERRÂNEAS}

Em regiões semi-áridas com precipitações pluviométricas da ordem de grandeza de $800 \mathrm{~mm}$ anuais, as lâminas de água infiltradas atingindo as águas subterrâneas em aquiíferos livres à semiconfinados são em geral consideradas superiores a $40 \mathrm{~mm}$ (FOSTER et al., 1994; SIMMERS, 1997). Assim sendo, as estimativas feitas no âmbito deste trabalho para o aquífero são 
aceitáveis. Em função desses resultados, admitindo condições de equilíbrio, ou seja, sem explotação das águas por poços, os recursos explotáveis poderiam ser, em uma primeiro aproximação, teoricamente tomados como equivalentes à recarga anual. Isto, entretanto, deve ser tomado com certa reserva, haja vista a ocorrência de águas salinizadas principalmente no setor sul da área, o que limita desta feita o uso das águas subterrâneas. Existem vários fatores que provavelmente podem estar contribuído com a salinização das águas neste setor: a) influência das rochas do embasamento cristalino que limitam o setor sul da área, b) baixa transmissividade do aquífero; c) baixa profundidade do nível das águas subterrâneas e d) direção do fluxo das águas subterrâneas no seu sentido de sul para norte. Ressalta-se, entretanto que maiores considerações a cerca da salinização e qualidade das águas não são considerados neste artigo.

A integração geral dos resultados dos estudos geológicos, geofísicos e hidrogeológicos levam à caracterização de subáreas ou zonas com diferentes possibilidades quanto aos recursos explotáveis, que em termos potenciais são apresentados a seguir (Figura 13):
Zona A: Localiza-se no setor norte da área e corresponde a zona de maior potencial hidrogeológico. $\mathrm{O}$ aqüífero Açu desenvolve espessura saturada em média de $150 \mathrm{~m}$ é transmissividade de $280 \mathrm{~m}^{2} / \mathrm{d}$. Os poços neste domínio, com profundidade em média de $160 \mathrm{~m}$, podem produzir até $100 \mathrm{~m}^{3} / \mathrm{h}$.

Zona B: É contígua a Zona A e de potencial hidrogeológico médio. A espessura saturada é da ordem de $50 \mathrm{~m}$ e a transmissividade do aqüífero é de $100 \mathrm{~m}^{2} / \mathrm{d}$. Os poços nesta zona com profundidades da ordem de $120 \mathrm{~m}$ podem produzir até $50 \mathrm{~m}^{3} / \mathrm{h}$.

Zona C: Situa-se no setor sul da área e é a zona que apresenta potencial hidrogeológico mais baixo. O aqüífero desenvolve espessura saturada de menos de $10 \mathrm{~m}$ até $50 \mathrm{~m}$, e a transmissividade é em geral inferior a $10 \mathrm{~m}^{2} / \mathrm{d}$. A produtividade de poços com $70 \mathrm{~m}$ de profundidade, é de no máximo $10 \mathrm{~m}^{3} / \mathrm{h}$.

Da análise empreendida e de acordo com a Figura 13, verifica-se que quase $50 \%$ da área de estudo $\left(660 \mathrm{~km}^{2}\right)$ apresenta limitações quanto a ocorrência e a explotação das águas subterrâneas por problemas lito-estruturais que limitam as espessuras saturadas dos aqüíferos Açu, tal como se verifica no setor sul da área.

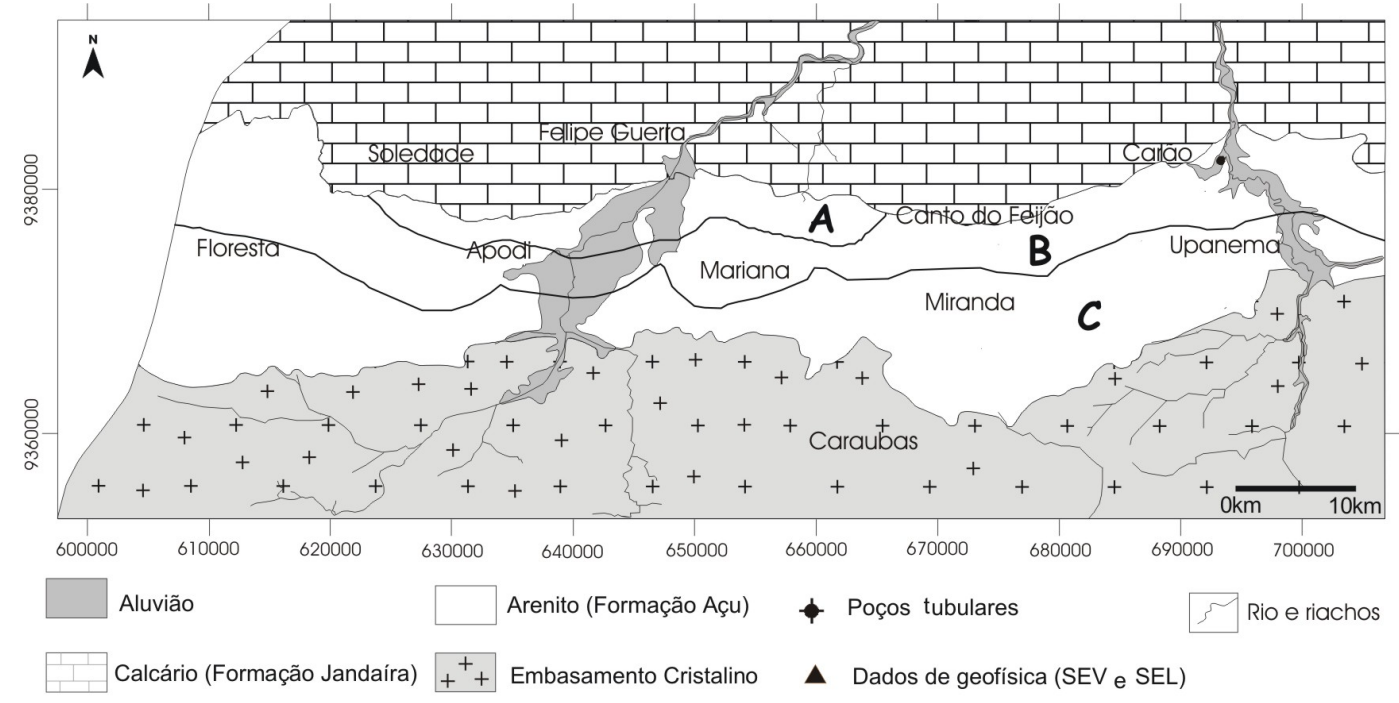

Zona A: Elevado Potencial Hidrogeológico - transmissividade de $280 \mathrm{~m}^{2} /$ dia; poços com $160 \mathrm{~m}$ de profundidade, em média, com capacidade de produção de até $100 \mathrm{~m}^{3} / \mathrm{h}$.

Zona B: Médio Potencial Hidrogeológico - transmissividade de $100 \mathrm{~m}^{2} /$ dia; poços com $120 \mathrm{~m}$ de profundidade, em média, com capacidade de produção de até $50 \mathrm{~m}^{3} / \mathrm{h}$.

Zona C: Baixo Potencial Hidrogeológico - transmissividade inferior a $10 \mathrm{~m}^{2} /$ dia; poços com até $70 \mathrm{~m}$ de profundidade, com capacidade de produção inferior a $10 \mathrm{~m}^{3} / \mathrm{h}$.

Figura 13. Potencialidades hidrogeológicas do aqüífero Açu

Figure 13 - Hidrogeologic potentialities of the Açu aquifer 


\section{CONCLUSÕES E RECOMENDAÇÕES}

Os aspectos lito-estruturais da Formação Açu, no domínio da área de estudo, condicionam a ocorrência de um aquífero livre sujeito a semiconfinamentos localizados, com diferentes comportamentos quanto a recarga e suas potencialidades. De conformidade com as dimensões, transmissividades e condições de recarga do aqüífero Açu, a maior parte das águas armazenadas no mesmo estão concentradas na faixa norte da área.

$\mathrm{O}$ volume de água que é disponibilizado atualmente à população é da ordem de 10 milhões de $\mathrm{m}^{3} / \mathrm{ano}$, o que representa menos de $20 \%$ da recarga anual (54 milhões de $\mathrm{m}^{3}$ ). Nestas condições, fica caracterizada a possibilidade de manutenção das descargas atuais que estão sendo captadas no aqüífero Açu e também a ampliação da oferta de água, que pode chegar a 40 milhões de $\mathrm{m}^{3} /$ ano. A preocupação neste caso está associada ao manejo do uso dessas águas, o qual requer poços criteriosamente locados, projetados e explotados de forma que não haja riscos de super explotação, salinização e ou outras formas que possam afetar os recursos e poços de captação. Neste sentido são feitas a seguir recomendações visando a melhoria do conhecimento do aqüífero Açu e uso racional dos seus recursos hídricos:

- Monitoramento dos níveis, das descargas bombeadas e da qualidade das águas o que permitirá avaliar periodicamente a eficiência das captações;

- Execução de sondagens de reconhecimento lito-estratigráfico na faixa norte da área;

- Execução de estudos geofísicos de detalhe em áreas específicas;

- Elaboração de teste de aquíffero de longa duração para avaliação da porosidade efetiva do aqüífero Açu.

Os resultados a serem obtidos com esses estudos complementares deverão levar a uma avaliação mais precisa das dimensões, parâmetros hidrodinâmicos e condições de explotação do aqüífero Açu, bem como a definição de estratégias de manejo que venham a assegurar o uso sustentável do aqüífero. 


\section{REFERÊNCIAS}

BRASIL-DNPM, Mapa Geológico do Estado do Rio Grande do Norte, escala 1:500.000; DNPM, UFRN,PETROBRAS,CRM, 1998.

CASTANY, G. Prospeccion y explotación de las águas subterráneas. Barcelona: Omega, 1975.

CUSTODIO, E. Estudio de los recursos de aguas subterráneas en la cuenca de la Riera de Carme e área de Capellades: alrededores de Igualada (Barcelona). Comisaría de Aguas del Pirineo Oriental y Serviço Geológico de Obras Públicas, Barcelona, 1973.

CUSTODIO, E; LLAMAS, M.R. Hidrologia Subterrânea. Barcelona: Omega, 2ed, Tomo I e II. 1976.

FETTER, C. W., Applyed Hydrogeology. $3^{\mathrm{a}}$ ed., Upper Saddle River: Prentice-Hall

FOSTER, S.S.D., MORRIS, B.L., LAWRENCE, A. R., Effects of urbanization on groundwater recharge. In: ICE Int Conf on Groundwater problems in Urban Areas, London, Proceedings... pp43-63,1994..

GERHART, J. M., Groundwater recharge and its effect on nitrate concentrations beneath a manures field site in Pennsylvania. Groundwater 24:483$489,1986$.

HALL, D. W.; RISSER, D. W., Effects of agricultural nutrient management on nitrogen fate and transport in Lancaster country, Pennsylvania. Water Resour Bull 29:55-76,1993.

HEALY, R. W.; COOK, P. G. Using groundwater levels to estimate recharge. Hydrogeologic J DOI 10.1007/s10040-001-0178-0. 2002.

IPT, Estudo hidrogeológico regional do Estado do Rio Grande do Norte, São Paulo, IPT/SIC (Relatório 15.795 - volume 1), 1982.

LERNER, D. N. Groundwater recharge. In: Saether $\mathrm{OM}$, de Caritat P (eds) Geochemical processes, weathering and groundwater recharge in catchments. AA Balkema, Rotterdam, pp 109-150. 1997.

LERNER, D.N., ISSAR, A.S., SIMMERS, I. Groundwater recharge. A guide to understanding and estimating natural recharge. IAH Int Contrib Hydrogeolog 8. Heinz Heise, Hannover, 345 pp. 1990.
MANUEL FILHO, J. M., Inventário Hidrogeológico Básico do Nordeste. Folha 10, Jaguaribe, NE. SUDENE, DD, Série Hidrogeologia $\mathrm{n}^{\circ} 30$, Recife. 1971.

MEDEIROS, W.E; DE SÁ, F.J. MEDEIROS, V.C.; LUCENA, L.R.F., Estrutura geológica do aquífero Açu na borda sul da Bacia Potiguar entre Apodi e Upanema, RN. Convênio CAERN/FUNPEC/UFRN. Relatório Técnico. 2001.

RASMUSSEN, W.C.; ANDREASEN, G.E. Hydrologic budget of the Beaverdam Creek Basin, Maryland. US Geol Surv Water -Supply Pap 1472: 106 p. 1959.

REBOUÇAS, A.C., Bacia Potiguar. Estudo Hidrogeológico. In: Bacia Escola de Hidrogeologia, Recife,

SUDENE/DD. (Série Hidrogeologia $n^{\circ} 15$ ). Relatório Interno, 1967.

SANFORD, W., Recharge and groundwater models: an overview. Hydrogeology Journal 10: DOI 10.1007/s10040-001-0173-5, 2002.

SANTOS, M. V., Estudo hidrogeológico da Planície Aluvial do Apodi, RN. Economicidade de poços para a irrigação, Recife, SUDENE/UFPE, 185p.1977.

SCANLON, B. R., COOK, P. G., Theme issue on groundwater recharge. Hydrogeologyc Journal DOI 10.1007/s10040-001-0175-3. 2002.

SCANLON, B. R., HEALY, R. W.; COOK, P. G., Choosing appropriate techniques for quantifying groundwater recharge. Hydrogeology Journal DOI 10.1007/s10040-001-0176-2. 2002.

SIMMERS, I, HENDRICKX, J. M. C., KRUSEMAN, G. P., RUSHTON, K. R., Recharge of phreatic aquifers in (semi)arid areas. IAH Int Contrib Hydrogeolog 19, AA Balkema, Rotterdam, 277 pp.1997.

VRIES, J.J.; SIMMERS, I.Groundwater recharge: an overview of processes and challenges. Hydrogeology Journal 10: DOI 10.1007/s10040-001-0171-7,2002. 